Illinois State University

ISU ReD: Research and eData

Theses and Dissertations

3-30-2014

\title{
Identification of Transcriptionally Quiescent Regions in the Neurospora crassa Genome
}

Katie Marie Groskreutz

Illinois State University, katie.groskreutz@gmail.com

Follow this and additional works at: https://ir.library.illinoisstate.edu/etd

Part of the Bioinformatics Commons, Biology Commons, and the Mathematics Commons

\section{Recommended Citation}

Groskreutz, Katie Marie, "Identification of Transcriptionally Quiescent Regions in the Neurospora crassa Genome" (2014). Theses and Dissertations. 111.

https://ir.library.illinoisstate.edu/etd/111

This Thesis is brought to you for free and open access by ISU ReD: Research and eData. It has been accepted for inclusion in Theses and Dissertations by an authorized administrator of ISU ReD: Research and eData. For more information, please contact ISUReD@ilstu.edu. 


\title{
IDENTIFICATION OF TRANSCRIPTIONALLY QUIESCENT REGIONS OF THE NEUROSPORA CRASSA GENOME
}

\author{
Katie M. Groskreutz \\ 62 Pages \\ May 2014 \\ Sexual reproduction and genetic exchange via meiosis are important and highly \\ conserved processes in many living organisms. Occasionally, complications occur during \\ meiosis that can result in chromosome abnormalities. In humans, improper chromosome \\ development can cause life altering disorders such as Down Syndrome, Edwards \\ Syndrome, and Patau Syndrome. Unfortunately, despite its importance, gaps remain in \\ our knowledge of how this process works. For instance, little is known about how \\ homolog identification occurs and what proteins identify matching chromosomes during \\ pairing. This fundamental process occurs early during meiosis and ensures proper \\ development of gametes.
}

Understanding the proteins involved during homolog pairing may be possible by studying a process called meiotic silencing by unpaired DNA (MSUD) in the eukaryotic fungus, Neurospora crassa. During MSUD, unpaired regions (or regions that do not match during homolog identification) are thought to produce special RNA molecules. Discovery of these molecules should help elucidate how unpaired DNA is identified. 
This is because it is possible that the proteins involved in identifying unpaired regions in MSUD are the same proteins that identify homologs in meiosis. Furthermore, these proteins could contribute to homology searches required for DNA repair, which could contribute in the development of cancer research.

To gain a complete understanding of unpaired DNA detection, the Neurospora crassa transcriptome must be identified. The transcriptome represents all the RNA molecules found within an organism at a certain point in time or stage of development. Knowledge of the transcriptome can be used in efforts towards identifying the theoretical RNA molecules of MSUD. The meiotic transcriptome can be determined by performing an RNA-seq analysis on all the RNA transcripts produced during meiosis. These RNA are then aligned to the $N$. crassa genome. Then, a special algorithm is used to identify key regions of the genome that may prove particularly useful in MSUD research (i.e. transcriptionally quiescent regions). Given the sheer size of the data sets required for identifying these regions, the algorithm must be time and memory efficient due to computational constraints. 


\section{IDENTIFICATION OF TRANSCRIPTIONALLY QUIESCENT \\ REGIONS OF THE NEUROSPORA CRASSA GENOME}

KATIE M. GROSKREUTZ

A Thesis Submitted in Partial Fulfillment of the Requirements for the Degree of

MASTER OF SCIENCE

Department of Mathematics

ILLINOIS STATE UNIVERSITY 
Copyright 2014 Katie M. Groskreutz 


\title{
IDENTIFICATION OF TRANSCRIPTIONALLY QUIESCENT REGIONS OF THE NEUROSPORA CRASSA GENOME
}

\author{
KATIE M. GROSKREUTZ
}

COMMITTEE MEMBERS:

Thomas Hammond, Chair

Papa Sissokho, Co-Chair

Michael Plantholt 


\section{ACKNOWLEDGEMENTS}

I would like to send a special thanks out to Tom Hammond. He has trusted me to help with his research and been more than patient in helping me learn the biology and programming surrounding this project. I would also like to thank Papa Sissokho and Mike Plantholt for serving on my thesis committee. Tyler Malone assisted me with performing the tedious BLAST analysis. I also feel it's very necessary to thank Scott Vossen for being my emotional rock through the roller coaster that has been graduate school. Both of my parents, Jeff and Linda Groskreutz, have supported me financially throughout my entire education, and I am eternally grateful to them as well. Last but not least, I cannot forget my amazing friends, who were always there to listen and support me.

K.M.G. 


\section{CONTENTS}

Page

ACKNOWLEDGEMENTS $\quad$ i

CONTENTS

TABLES $\quad$ iv

FIGURES

CHAPTER

I. BIOLOGICAL BACKGROUND 1

1.1: Biological Background 1

1.1.1: Meiosis 1

1.1.2: DNA, RNA, Transcription \& Translation 3

1.1.3: An Introduction to Neurospora crassa 4

1.1.4: Genomic Invaders 4

1.2: Genomic Defenses in Neurospora crassa 5

1.2.1: DNA Methylation \& RIP 6

1.2.2: MSUD 6

1.3: Importance of Quiescent Regions $\quad 8$

$\begin{array}{ll}\text { II. METHODS } & 10\end{array}$

2.1: The Data Sets $\quad 10$

2.1.1: RNA-Seq 10

2.1.2: Description of Data Sets 11

2.2: Bowtie 12

2.2.1: Introduction to Bowtie 12

ii 
2.2.2: Burrows-Wheeler Transformation \&

EXACTMATCH

2.2.3: Identifying Inexact Matches

2.2.4: Bowtie Compared to Other Alignment

Programs

2.2.5: Bowtie Features Used

2.3: Perl Scripts -- Identifying Quiescent Regions

2.3.1: Identify Mapped Regions -- Convert CIGAR Scores

2.3.2: Identify Quiescent Regions -- Memory Efficient Algorithm

2.3.3: Identify Quiescent Regions -- Speed Efficient Algorithm

III. RESULTS

3.1: Chromosome Map

3.2: Analysis of Largest Quiescent Regions

3.3: Quiescent Region Summary Statistics

3.4: Analysis of Algorithms

IV. DISCUSSION

4.1: Hypotheses About Transcriptional Quiescence

4.1.1: Evolutionary Origins of the Quiescent Regions

4.1.2: GC/AT Content

4.2: Memory Efficiency vs. Speed Efficiency

V. CONCLUSIONS

5.1: Final Thoughts

40

5.2: Future Research

40

REFERENCES

APPENDIX:

Perl Scripts

46 


\section{TABLES}

Table $\quad$ Page

1. Summary of Proteins Involved in MSUD 8

2. Description of CIGAR Operators from SAM Format 17

3. Centromere Locations 27

4. Top BLAST Results for Data Set $1005 \quad 28$

5. Top BLAST Results for Data Set F201 29

6. Top BLAST Results for Data Set SRR751454 30

7. Top BLAST Results for Data Set SRR755946 31

8. Summary Statistics: Size of Quiescent Regions 32

9. Summary of Results from Hypothesis Test for Differences in GC Content 33

10. Memory Efficient Algorithm Times by Subroutine 34

11. Time and Memory Efficiency of Algorithms 35 


\section{FIGURES}

Figure $\quad$ Page

1. Description of Meiosis 2

2. Depiction of Transposable Elements 5

3. Neurospora crassa Meiotic Silencing Model 7

4. Burrows-Wheeler Matrix Example 13

5. Last-First Mapping Example 14

6. Example Output from Bowtie in SAM Format 18

7. Scenarios for Memory Efficient Algorithm 21

8. Chromosome Map for Combine Data Sets 1005 and F201 25 


\section{CHAPTER I}

\section{BIOLOGICAL BACKGROUND}

\section{1: Biological Background}

This section is intended to give a brief description of the biological processes that are relevant to this project.

\subsection{1: Meiosis}

Meiosis is a specific type of cell division used for the production of sex cells (spores in the case of fungi) in eukaryotes. The steps involved in meiotic cell division are similar to those for other somatic cells, which divide through a well-known process called mitosis. Meiosis, shown in Figure 1, begins with a duplication of chromosomes (Figure 1a). Next, each chromosome pairs with its homolog (Figure 1b). This pairing allows for the exchange of genetic material, which contributes to genetic variation, through a process called crossing over. Homologous chromosomes are moved to opposite poles of the cell and the original cell is then split into two daughter cells (Figure 1c). This process repeats again, this time without initial duplication of the chromosomes (Figure 1d). This results in each of the two daughter cells dividing to produce four cells with half the genetic information (Figure 1e). 


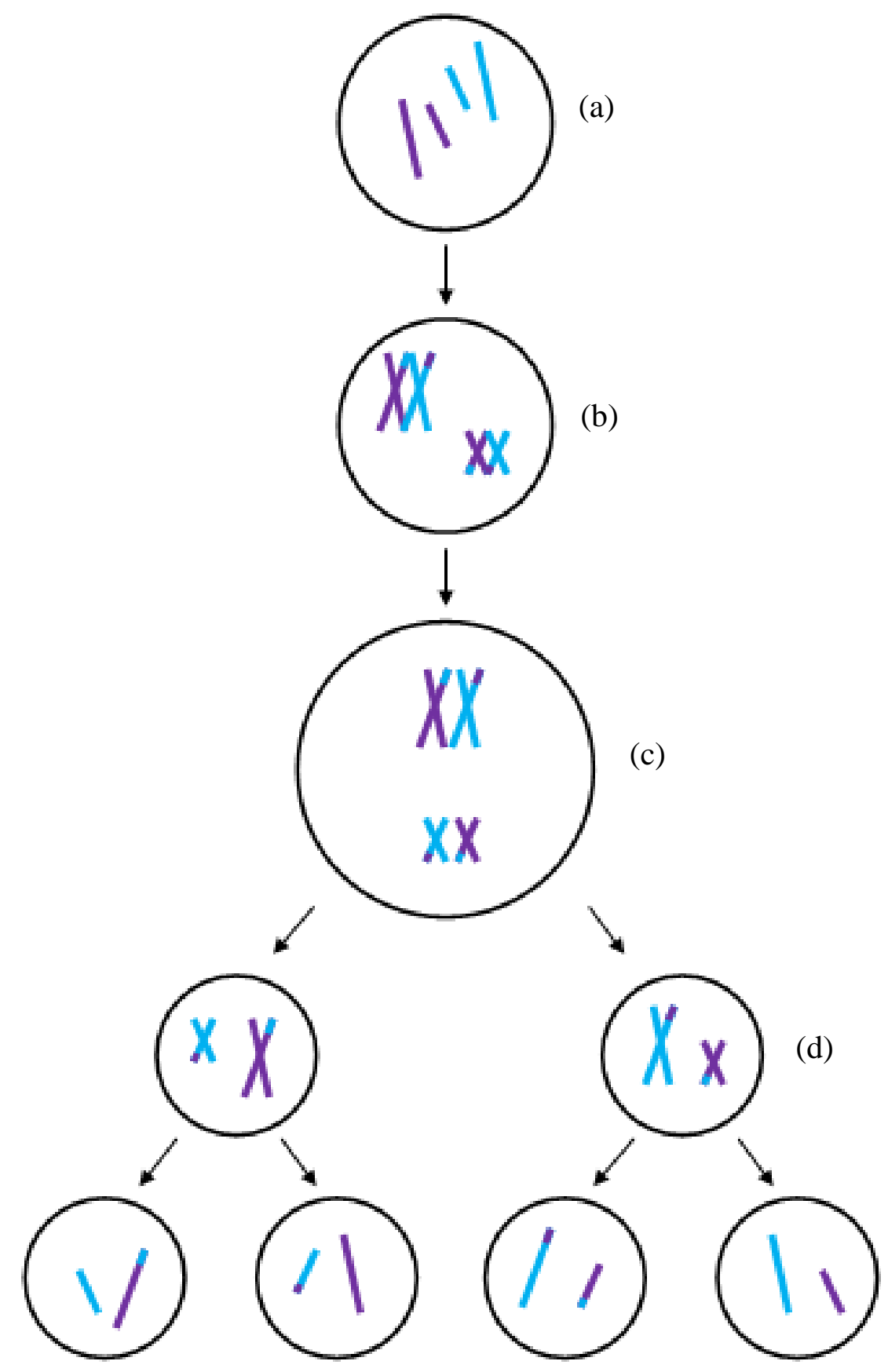

(e)

Figure 1. Description of Meiosis.

Chromosomes in a single cell duplicate, align, exchange genetic material, then segregate to form two new cells that are genetically different than the parent cell (a-d). Haploid cells are produced in the final stage of meiosis (e). 


\subsection{2: DNA, RNA, Transcription \& Translation}

DNA (deoxyribonucleic acid) is a molecule found in all living organisms that contains the genetic instructions for protein synthesis. DNA is made up of four different nucleotide bases: adenine $(A)$, thymine $(T)$, guanine $(\mathrm{G})$ and cytosine $(C)$. The central dogma of molecular biology explains the process of how DNA's genetic information is used to create functional proteins. Such proteins are responsible for representing the physical traits or the phenotype that we can see, i.e. height or hair color.

Transcription is the first step in this process. Double stranded DNA is transcribed into single stranded RNA (ribonucleic acid) via transcription. RNA is similar to DNA in that it has four nucleotide bases, except instead of thymine it has uracil (U). The newly created RNA strand is known as the "complement" to its parent DNA strand. In the case of DNA, a complement means that adenine pairs with thymine (uracil in RNA) and guanine pairs with cytosine.

Once the DNA has been transcribed, the RNA molecules can take on many different varieties each of which is responsible for a special role, such as protein production or gene regulation. There are a few types of RNA that are important to know for this project. The first and most common type is messenger RNA or mRNA. Each mRNA contains a specific sequence that codes for an explicit amino acid chain. This amino acid chain forms a functional protein product that gives rise to a phenotype. The process by which proteins are produced from mRNA is called translation. Other types of RNA, namely, aRNA, dsRNA, and masiRNA, are also important to know for the 
background of this project. However, they will be introduced and discussed in section 1.2.2.

\subsection{3: An Introduction to Neurospora crassa}

Neurospora crassa is a type of bread mold belonging to the phylum Ascomycota. $N$. crassa is a model organism for genetics research projects because it is easily maintained and cultured and has a rich history that makes use of well established protocols for genetic and biochemical techniques (Davis 2000). In particular, N. crassa has played a crucial role in the understanding of genome defense systems and gene silencing mechanisms, making it an important organism in which to better understand these processes (Davis 2000).

\subsection{4: Genomic Invaders}

Transposable elements are mobile sequences found within the genomes of most organisms. They often replicate, and then move to new locations in their host genomes. Transposable elements can be dangerous because they can insert themselves into coding regions or regions that regulate gene expression. This process is shown in Figure 2. The structure of most eukaryotic genomes suggests that they contain a relatively large proportion of transposable elements (Slotkin and Martienssen 2007). N. crassa, on the

other hand, shows little evidence of these genome manipulators (Cambareri et al. 1991).

Given the potentially harmful nature of genomic invaders, such as transposable elements and viruses, it is not surprising that organisms have evolved different approaches to handle them. $N$. crassa utilizes many different methods in an attempt to 
keep these elements out of their genome (such methods are discussed in detail below).

Plants, on the other hand, appear to have embraced the dynamic genome, as over half of

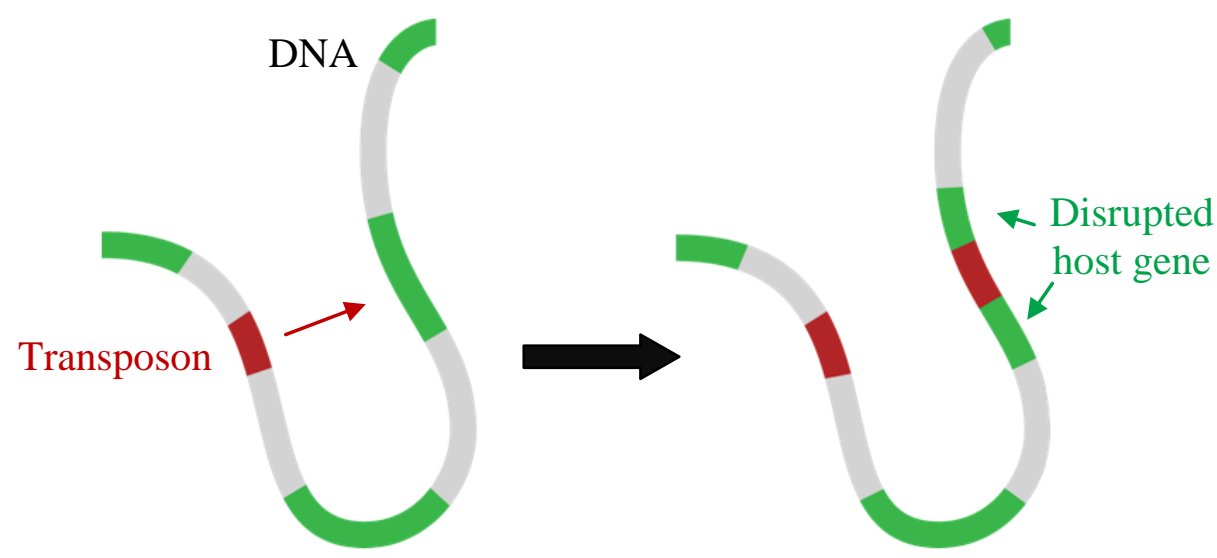

Figure 2. Depiction of Transposable Elements.

Transposable elements are mobile sequences that often replicate and move to a new location in their host genomes. Transposable elements can be dangerous because they can insert themselves into coding regions or regions that regulate gene expression. Figure adapted from Norris 2013.

their genome can be comprised of transposable elements (Feschotte et al. 2002).

\section{2: Genomic Defenses in Neurospora crassa}

Within the genome, there can be potentially harmful hitchhikers, like viruses or transposable elements, which can insert themselves into new locations the genomic code. There are many different ways organisms have evolved to defend their genomes against these 'selfish genetic elements'. $N$. crassa, in particular, has developed several different methods. They include DNA methylation, repeat point mutation (RIP), and meiotic silencing by unpaired DNA (MSUD) (Galagan et al. 2003, Borkovich et al. 2004). 


\subsection{1: DNA Methylation \& RIP}

The process of DNA methylation serves many purposes. It silences genes by the addition of a methyl group to a nucleotide base. Also, during gamete development, DNA methylation plays an important role for ensuring that embryonic stem cells differentiate into other specific cell types. This is a permanent process that prevents a cell from changing to another type (Lister et al. 2009). DNA methylation has also been found to play a critical role in the development of cancerous tumors (Foss et al. 1993).

Occurring during the premeiotic phase in certain fungal species, RIP (repeat induced point mutation) acts on duplicated sequences within DNA, such as transposable elements that insert themselves in the genome at multiple locations, by inducing C-to-T and G-to-A mutations (Kelly \& Aramayo 2007, Freitag et al 2002, Hood 2005). This process silences these sequences to protect the native genome against foreign invaders. It is believed that such alterations by RIP may trigger cytosine DNA methylation (Singer et al. 1995). It is also hypothesized to be the reason $N$. crassa has so few duplicated genes and almost no transposable elements found within its genome (Galagan et al. 2004). Essentially, the only transposable elements that exist are possible relics of old transposons that have been highly mutated by RIP (Singer et al. 1995).

\subsection{2: MSUD}

A process called meiotic silencing by unpaired DNA (MSUD) in N. crassa may better help us understand the largely obscure process of homolog pairing. MSUD occurs when a mechanism identifies regions of the chromosome that do not "pair" during homolog identification in meiosis (Figure 3 (1)) (Shiu et al. 2001). Currently, little is 
known about the proteins that work to identify homologous regions within chromosomes.

Evidence suggests that $N$. crassa, more so than other organisms, requires a higher proportion of matches for a chromosome to be considered a homologous pair (Pratt et al. 2004).

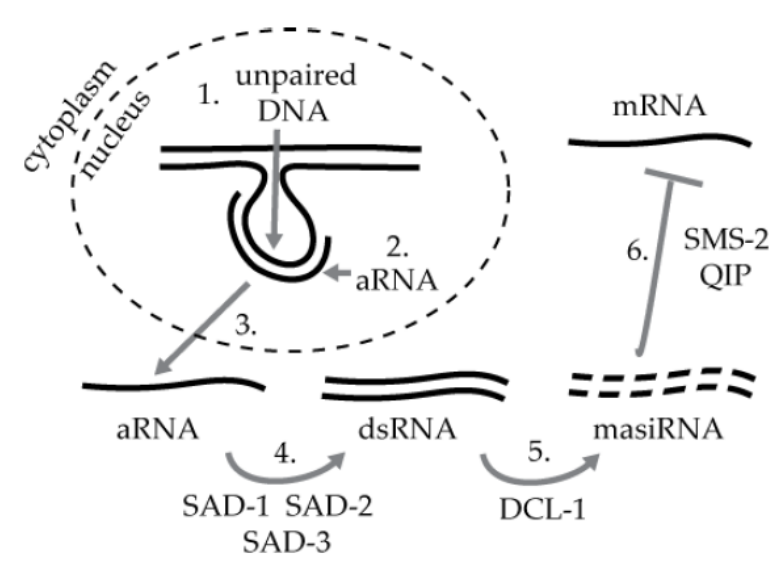

Figure 3. Neurospora crassa Meiotic Silencing Model.

The first three steps of this process are performed by unknown proteins. Aberrant RNA may be created from unpaired regions of DNA that do not have a homologous pair. It would then be converted to dsRNA, then masiRNA (steps 4 and 5). These masiRNA molecules silence complimentary mRNA (step 6). The dashed ellipse represents the nuclear membrane. Figure adapted from Hammond et al. 2011.

The current working model of MSUD is as follows: once an unpaired region is found, a theoretical aberrant RNA (aRNA) molecule is synthesized from that region's DNA (Figure 3 (2)). The aRNA may then be exported out of the nucleus (Figure 3 (3)), before it is converted to dsRNA (double stranded RNA) by RdRP (RNA-dependent RNA polymerase). Now, Dicer, a protein that cleaves dsRNA, can convert the dsRNA into siRNAs (short interfering RNA) (Figure 3 (5)), which are 20-25 base pairs in length (Galagan et al. 2003, Lee et al. 2003, Borkovich et al. 2004, Catalanotto et al. 2004). When these siRNAs are a part of the meiotic silencing process, they are called meiotic- 
silencing associated short interfering RNA (masiRNA) (Hammond et al. 2013). These masiRNA are likely incorporated into an RNA-induced silencing complex (RISC), which uses them as templates for identifying complementary mRNA for destruction or translational suppression (Figure 3 (6)). Thus, complementary mRNA is degraded no matter if is from an unpaired or paired sequence. Additional information about the proteins involved in MSUD can be found in Table 1.

Since little is known of the proteins that identify homologs, it is possible that the proteins involved in identifying unpaired regions in MSUD could also be the same proteins that identify homologs in meiosis.

Table 1. Summary of Proteins Involved in MSUD.

\begin{tabular}{|c|c|c|}
\hline Protein & Location & Function \\
\hline SAD-5 & nuclear & unknown function $^{\mathrm{a}}$ \\
\hline SAD-1 & perinuclear & turns aRNA into dsRNA $^{\mathrm{b}}$ \\
\hline SAD-2 & perinuclear & serves as a scaffold for other MSUD proteins $^{c}$ \\
\hline SAD-3 & perinuclear & helps SAD-1 ${ }^{\mathrm{d}}$ \\
\hline SAD-4 & perinuclear & unknown function $^{a}$ \\
\hline DCL-1 & perinuclear & a Dicer protein that cleaves dsRNA into siRNAs ${ }^{\mathrm{e}}$ \\
\hline SMS-2 & perinuclear & uses siRNA to target complementary mRNAs ${ }^{f}$ \\
\hline QIP & perinuclear & processes siRNAs into single strands $^{\mathrm{g}, \mathrm{h}}$ \\
\hline
\end{tabular}

Sources: Hammond et al. 2013 ${ }^{\mathrm{a}}$, Shui and Metzenberg 2002 ${ }^{\mathrm{b}}$, Shiu et al. 2006 ${ }^{\mathrm{c}}$, Hammond et al. 2011 ${ }^{\mathrm{d}}$, Alexander et al. $2008^{\mathrm{e}}$, Lee et al. $2003^{\mathrm{f}}$, Lee et al. $2010^{\mathrm{g}}$, Xiao et al. $2010^{\mathrm{h}}$

\section{3: Importance of Quiescent Regions}

Aberrant RNA or aRNA that is created from unpaired regions is currently theoretical. One reason why it had not been detected may be that it is difficult to distinguish it from other forms of RNA. Some attempts to do so have been made without success using standard molecular biology techniques. Here we will try to identify the most transcriptionally quiescent regions of the genome with the use of next-generation sequencing. Once the regions have been identified, we will try to force the creation of 
aRNA in these regions by unpairing them during meiosis. This novel technique for finding aRNA has never been attempted before. If this is successful, all the transcripts from the unpaired loci should be aRNA. Some of the proteins involved in aRNA generation may be involved in the recognition of unpaired DNA, others may be involved in aRNA generation, and others may be involved in later stages of the process.

To gain a complete understanding of unpaired DNA detection and the proteins that drive the mechanism, all of the regions that are unpaired during MSUD must be identified throughout the $N$. crassa genome. 


\section{CHAPTER II}

\section{METHODS}

\section{1: The Data Sets}

This section outlines the data sets and methods used for gathering and analyzing data.

\subsection{1: RNA-Seq}

A transcriptome is known as the set of all RNA molecules that are produced in a cell. RNA-Seq uses deep-sequencing technologies to give us a precise measurement of the level of transcripts in an individual transcriptome. In general, this information is important for determining the functional elements in the genome at any given point in time. RNA-Seq is often used for determining the structure of genes in terms of location or splicing patterns and quantifying changes in expression levels at different time periods. This method is emerging as the dominant form for measuring transcriptomes, as opposed to using microarrays, since sequencing technologies have become cheaper and more accurate (Wang et al. 2009). 


\subsection{2: Description of Data Sets}

The data sets used for this project come from four $N$. crassa crosses and represent their meiotic transcriptomes obtained via RNA-Seq. There are two types of data sets: one that contains only large RNA's (>30 nucleotides) and one that only contains small RNA's (<30 nucleotides). Data sets F201 (SRR957218) and 1005 (SRR957223) are the large RNA data sets and SRR751454 and SRR755946 are the small RNA data sets. The goal of this project is to analyze the transcriptome of Neurospora and to map its quiescent regions. It is possible that regions producing large RNA are different from those that produce small RNA. Since we are looking for regions that have no detectable RNA at all, it is important to look at both types of data sets.

- Data Set F201 (SRR957218): This data set represents an RNA-seq analysis of all RNA from the fruiting bodies and associated vegetative tissue from a cross between strains P9-42 (Oak Ridge WT $a$ ) and F201 $(f l A)$.

- Data Set 1005 (SRR957223): This data set represents an RNA-seq analysis of all RNA from the fruiting bodies and associated vegetative tissue from a cross between strains P6-07 ( rid A) and F2-26 (rid; fl a). This cross is theoretically the same as the one performed for data set F201 $(f l A)$, except that both strains used in the cross are mutated in a gene known as rid.

- Data Set SRR751454: This data set represents an RNA-seq analysis of the small RNA from the fruiting bodies and associated vegetative tissue of a cross between strains P3-08 (Oak Ridge WT $a$ ) and F201 $(f l A)$. It was downloaded as a small RNA data set from NCBI. 
- Data Set SRR755946: This data set represents an RNA-seq analysis of the small RNA from the fruiting bodies and associated vegetative tissue of a cross between P3-08 (Oak Ridge WT $a)$ and F5-39 $\left(r^{\triangle} ; f l A\right)$. It was downloaded as a small RNA data set from NCBI.

\section{2: Bowtie}

This section is intended to describe how Bowtie, a free, open-source alignment program, works and is used for identifying the quiescent regions or regions of no transcription within the Neurospora crassa genome.

\subsection{1: Introduction to Bowtie}

Bowtie is a fast, yet memory efficient alignment program that can be run on a typical desktop computer. It works to align short sequences, such as 'reads' from an RNA-seq analysis, to a reference genome. Such efficiency is achieved by use of a novel indexing strategy called a Burrows-Wheeler index along with a Burrows-Wheeler transformation (BWT) (Langmead et al. 2009).

\subsection{2: Burrows-Wheeler Transformation \& EXACTMATCH}

The BWT is a simple permutation of all the characters in a string. For instance, let $\mathrm{T}^{*}=$ 'TAGTTAC' be a string of text. Step $1 \mathrm{in}$ BWT is to append a $\$$ to the front of T* (See Figure 4). ' $\$$ ' is set to be lexicographically less than all other characters in $\mathrm{T}^{*}$. Step 2 is to create a Burrows-Wheeler matrix. The rows contained in the matrix are comprised of all the cyclic rotations of $\mathrm{T}^{*}$. The next step (Step 3) is to sort the matrix 
lexicographically by the first character in each row. The Burrows-Wheeler transformation of $\mathrm{T}^{*}\left(\mathrm{BWT}\left(\mathrm{T}^{*}\right)\right)$ is the rightmost column of the matrix (Step 4).

The Burrows-Wheeler matrix has the property of last-first (LF) mapping. That is, the $\mathrm{i}^{\text {th }}$ occurrence of a character $\mathrm{X}$ in the last column (or BWT(T*)) corresponds to the $\mathrm{i}^{\text {th }}$ occurrence of $\mathrm{X}$ in the first column (or the lexicographically sorted $\mathrm{T}^{*}$ ). The last-first mapping property is necessary for the algorithms that use the BWT to search a text for an alignment.

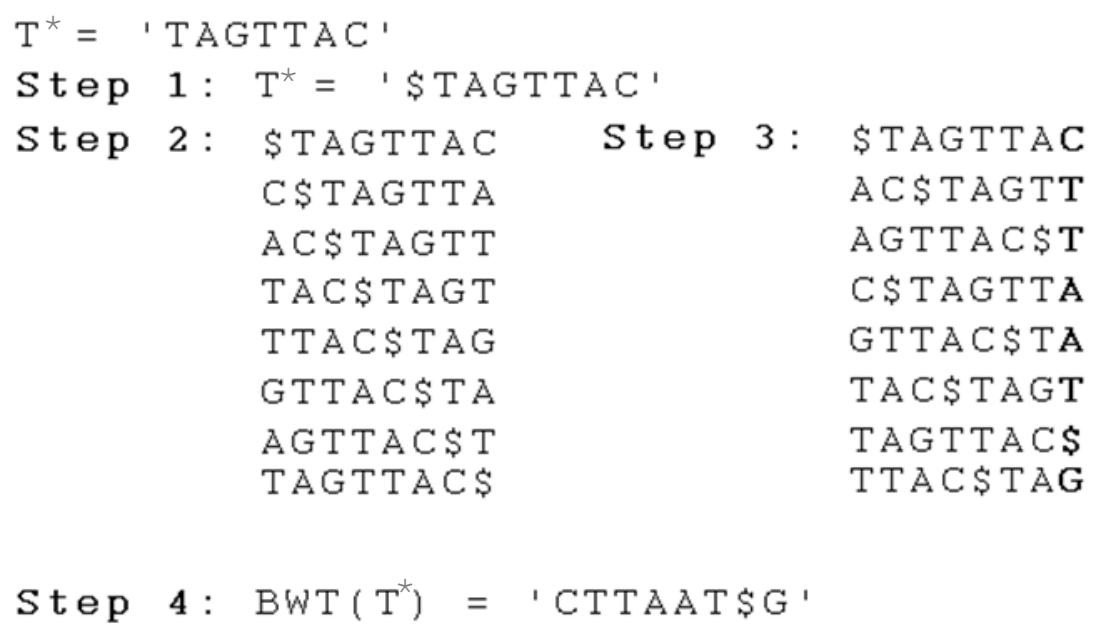

Figure 4. Burrows-Wheeler Matrix Example.

This figure shows how a Burrows-Wheeler matrix is created in order to apply the Burrows-Wheeler transformation to a string of text, $\mathrm{T}^{*}$. Figure adapted from Langmead et al. 2009.

This LF mapping is used in Bowtie's EXACTMATCH algorithm (Figure 5) to find where a short read matches a reference sequence. The example in Figure 5 uses the sequence 'TTA' as a read sequence to show how the EXACTMATCH algorithm works. The LF mapping method requires us to start with the last letter of the read, 'A', as seen in Figure 5 (a). Next, we identify the range of the rows that start with the letter A. Follow 
those rows that start with A to the last column of the matrix. Of these rows, the ones that contain T's (the next letter moving backwards through the read) correspond to the first and second occurrences of $\mathrm{T}$ in the last column. As shown in Figure 5 (b), the process starts over. We come back to the first column of the matrix to find the first and second occurrences of T's and again follow them to the rightmost column of the matrix. The next letter moving backwards through the read is a ' $\mathrm{T}$ '. In the rightmost column this is the third occurrence of T. This is continued for each of the characters in the read until the range equals one. Then the EXACTMATCH algorithm is done and the alignment of the read to the reference is complete.

\begin{tabular}{|c|c|c|c|}
\hline (a) $\mathrm{TTA}$ & TTA & (c) & TTA \\
\hline$\$ T A G T T A C$ & \$TAGTTAC & & TAGTTAC \\
\hline $\mathrm{AC}$ TAGTT & AC\$TAGTT & & A $\$$ TAGTT \\
\hline$\rightarrow A G T T A C \$ T$ & AGTTAC\$T & & AGTTAC\$T \\
\hline C\$TAGTTA & C\$TAGTTA & & DTAGTTA \\
\hline GTTAC\$TA & GTTAC\$TA & & GTTAC\$TA \\
\hline TAC\$TAGT & TAC\$TAGT & & $\Gamma \mathrm{AC}$ TAGT \\
\hline TAGTTAC\$ & TAGTTAC\$ & & ГAGTTAC\$ \\
\hline TTAC\$TAG & TTAC\$TAG & & $\Gamma \mathrm{TAC} \mathrm{TAG}$ \\
\hline Range: 2 & Range: 2 & & Range: 1 \\
\hline
\end{tabular}

Figure 5. Last-First Mapping Example.

This figure shows how last-first mapping works to find where a read aligns to the reference sequence. Figure adapted from Langmead et al. 2009.

\subsection{3: Identifying Inexact Matches}

It is possible for sequencing errors or genuine differences to exist between reads and the reference sequence. Therefore, the EXACTMATCH algorithm may be insufficient in many cases. Once Bowtie has gone through the EXACTMATCH 
algorithm without identifying an exact match for a read, it proceeds to look for an inexact match. It does so in a similar manner to EXACTMATCH. A position that has already been matched within the read is selected and a different base is substituted in its place. This introduces a mismatch into the read. Then the EXACTMATCH algorithm continues to check for an alignment with that mismatch. If no such alignment is found, another position is randomly selected for a mismatch to be introduced.

Because Bowtie searches in this greedy, randomized, depth-first search manner, it may not find the best alignment that exists. Options such as 'best' will improve the alignment in terms of number of mismatches or quality. However, this will slow the program by as much as two or three times as much as the default mode.

\subsection{4: Bowtie Compared to Other Alignment Programs}

Many different topics are included as part of testing the "goodness" of an alignment program, such as CPU time, peak memory footprint, and percentage of reads aligned. In some of these performance aspects, other popular open-source alignment programs, such as SOAP and Maq (Li et al. 2008a, Li et al. 2008b), have comparable performance statistics. For instance, all three programs can achieve similar percentage of reads aligned with nearly equivalent peak memory footprint. However, Bowtie far exceeds the other two in terms of speed. For example, when aligning a set of reads with a length of 76 base pairs Bowtie takes 19 minutes of CPU time (with memory footprint: 1,323 Mb, reads aligned: $44.5 \%$ ) compared to Maq's 4 hours and 45 minutes (memory footprint: 1,155 Mb, reads aligned: 44.9\%) (Langmead et al. 2009). Additionally, Bowtie 
has the option, unlike other programs, to achieve a higher percentage aligned at the cost of speed.

\subsection{5: Bowtie Features Used}

Bowtie has many options, such as 'best' described above, that give it flexibility for speed, memory usage and output formats. Below are a list of the features used in this project:

- $\quad-p$ : This option increases the size of bowtie's memory footprint, but increases its speed (scale: $1-8)$. This causes it to search with a specified number of parallel threads on different cores.

- --phred33: When sequenced, each nucleotide base is assigned a certain letter based on quality or confidence of the machine doing the sequencing. This feature tells Bowtie that Phred quality scores are provided with the read sequences.

- --local: This feature allows for some characters on each end to be omitted from the alignment (also known as soft clipping).

- $\quad$-a: This feature tells bowtie to report all valid alignments.

\section{3: Perl Scripts -- Identify Quiescent Regions}

This section describes the Perl scripts and algorithms that were developed to identify the quiescent regions of the Neurospora crassa genome. 


\subsection{1: Identify Mapped Regions -- Convert CIGAR Scores}

Bowtie outputs a file in SAM format (Sequence Alignment/Map Format) (Langmead and Salzberg 2012). The SAM format is tab-delimited and begins with a header section. Each line in the header begins with an '@' identifier to differentiate it from the alignment section which follows. The alignment section has different fields that give information about the alignment of each read, i.e. reference sequence name, read alignment start position, a CIGAR (Compact Idiosyncratic Gapped Alignment Report) score, etc. (Li et al. 2009).

The fields that provided the most useful information for this project were the read start position and the CIGAR score. A CIGAR string gives information about the alignment of each read. It tells where there were matches, insertions, deletions, clipped regions, etc. An example of a CIGAR string (see Figure 6) would be '8M2I4M1D3M'. Each number is followed by an operator (letter). For a list of operators see Table 2. In the example, the first 8 bases match exactly to the reference then 2 bases are inserted into the reference, and so on. Other examples of read alignments and their corresponding CIGAR scores are provided in Figure 6.

Table 2. Description of CIGAR Operators from SAM Format.

\begin{tabular}{|c|l|}
\hline Op & Description \\
\hline M & Alignment match \\
I & Insertion to the reference \\
D & Deletion from the reference \\
N & Skipped region from the reference \\
S & Soft clipping \\
P & Padding (silent deletion from padded reference) \\
\hline X & Sequence mismatch \\
\hline
\end{tabular}


A Perl script was written to parse each CIGAR score in order to determine the length of each read based on this score. Once the length was determined, the start and end position of each read was calculated. Knowing the start and end positions for each read is necessary to determine which regions of the N. crassa genome (the reference sequence) had reads mapped to them.

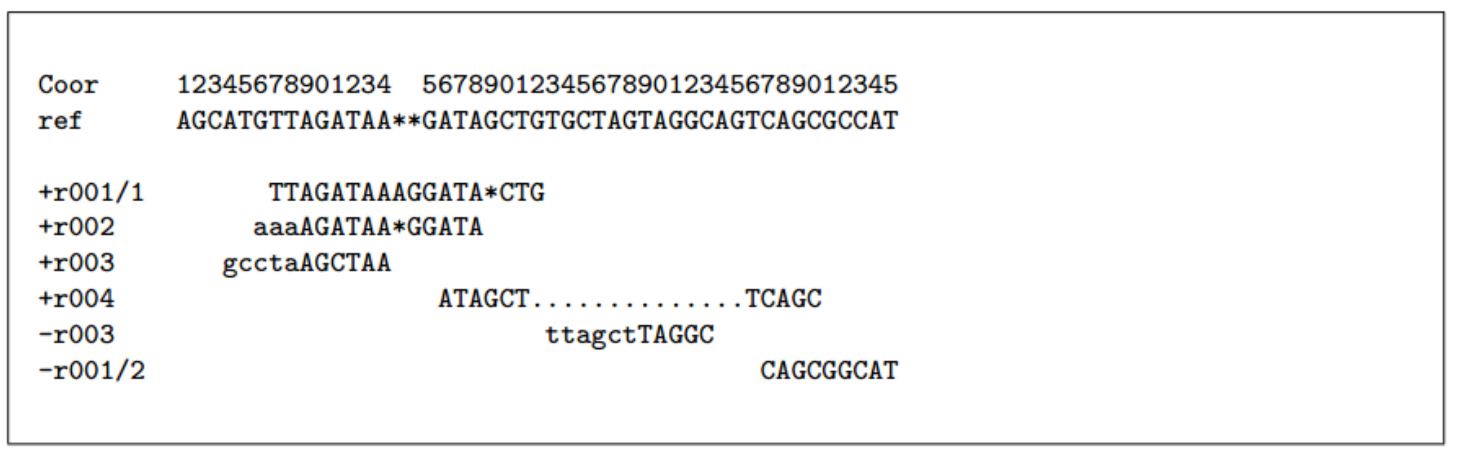

The corresponding SAM format is:

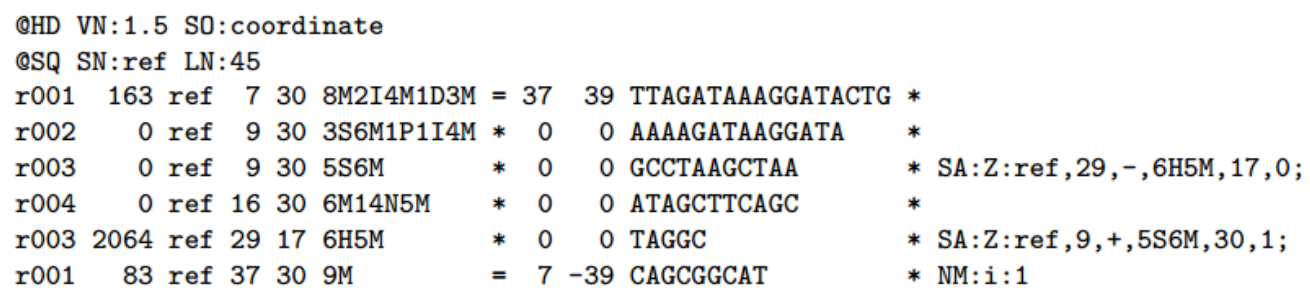

Figure 6. Example Output from Bowtie in SAM Format.

This figure shows an example of multiple read alignments with their corresponding output in SAM format. Column 4 contains the start position of the read. Column 6 contains the CIGAR score. Figure adapted from Li et al 2009.

\subsection{2: Identify Quiescent Regions -- Memory Efficient Algorithm}

Once the start and end positions for each read have been determined, the next step is to identify which regions of the $N$. crassa genome have reads mapped to them. One of the major challenges of this task is to create an algorithm that can do this in the memory 
footprint allowable on a personal computer. Consider that the four data sets have a combined total size of over $200 \mathrm{~Gb}$ and the largest of the data sets has over 215 million lines.

This algorithm is described in detail below, but first, let a range be defined as a set of start and end points representing some superset of one or more reads.

\section{Initial set up:}

- Create two arrays; startArray $=\{\}$, endArray $=\{\}$. These arrays will mark the start and end points of the currently mapped regions and store only the necessary values to optimize memory usage. Throughout this algorithm, transformations will be performed on the ranges stored in the arrays to ensure that at any point throughout the application, they represent the minimal set, M, of ranges required to describe the data set as a whole.

\section{First line:}

- Parse or extract the start and end positions for the first read.

- Push these values to the start and end arrays, respectively. startArray $=\left\{s_{1}\right\}$, endArray $=\left\{e_{1}\right\} . M=\left\{\left(s_{1}, e_{1}\right)\right\}$.

\section{Subsequent lines:}

- Parse the next line as a range representing the single read; $R=\left(r_{s}, r_{e}\right)$.

- Find the index, $i$, where $r_{s}$ falls in the startArray such that $r_{s} \leq \operatorname{startArray[i].~We~}$ can use this index, $\mathrm{i}$, to ensure that the ranges stored in the arrays always stay in sorted order. Let $A=(\operatorname{startArray}[i-1]$, endArray $[i-1])=\left(a_{s}, a_{e}\right)$ and $B=(\operatorname{startArray}[i]$, endArray $[i])=\left(b_{s}, b_{e}\right)$. 
- Determine which of the following scenarios apply for the new range, $\mathrm{R}$, and perform the associated action. Each scenario is shown in Figure 7.

- Scenario 1: Composition. Composition occurs when $\mathrm{R} \subset \mathrm{A}$. That is, $\mathrm{r}_{\mathrm{e}} \leq \mathrm{a}_{\mathrm{e}}$

- Action: Do nothing. This read is already covered by our arrays. That is, $\mathrm{R} \subset \mathrm{M}$.

- Scenario 2: Right Extension. When $r_{s} \leq a_{e}$ and $r_{e}<b_{s}$, a right extension of A occurs.

- Action: Transform A into $\left(\mathrm{a}_{\mathrm{s}}, \mathrm{r}_{\mathrm{e}}\right)$.

- Scenario 3: Connection. When $\mathrm{R}$ joins $\mathrm{A}$ and $\mathrm{B}$, then $\mathrm{A}$ and $\mathrm{B}$ form a connection by $R$. That is, $r_{s} \leq a_{e}$ and $r_{e} \geq b_{s}$.

- Action: If $r_{e}<b_{e}$, then transform A into $\left(a_{s}, b_{e}\right)$ and delete $B$, adjusting trailing indices accordingly. If $r_{e}>b_{e}$, transform A into $\left(a_{s}, r_{e}\right)$ and delete B. Ensure $r_{e}$ does not extend into any trailing ranges of $\mathrm{M}$. If it does, adjust ranges of $\mathrm{M}$ similarly.

- Scenario 4: Insertion. If $\mathrm{R}$ is mutually exclusive of $\mathrm{A}$ and $\mathrm{B}$, then an insertion occurs. This implies that $r_{s}>a_{e}$ and $r_{e}<b_{s}$.

- Action: Insert $\mathrm{R}$ into $\mathrm{M}$ at index i, incrementing the existing indices $\geq \mathrm{i}$ by 1 .

$\circ$ Scenario 5: Left Extension. If $r_{s}>a_{e}, r_{e} \geq b_{s}$, and $r_{e} \leq b_{e}$, there is a left extension of B.

- Action: Transform B into $\left(r_{s}, b_{e}\right)$. 
- Scenario 6: Double Extension. A double extension occurs when $r_{s}>a_{e}$ and $r_{e}>b_{e}$, which means B needs to be extended to the right and the left.

- Action: Transform B into $\left(r_{s}, r_{e}\right)$. Check to make sure $r_{e}$ does not extend into any trailing ranges of $\mathrm{M}$. If it does, adjust ranges of $\mathrm{M}$ accordingly.

\section{Identify quiescent regions:}

- The quiescent regions can then be described as the set $\mathrm{Q}$, where $\mathrm{Q}$ is the inverse image of $\mathrm{M}$.

\section{Extract desired results:}

- Determine 35 largest quiescent regions from each data set for further analysis.

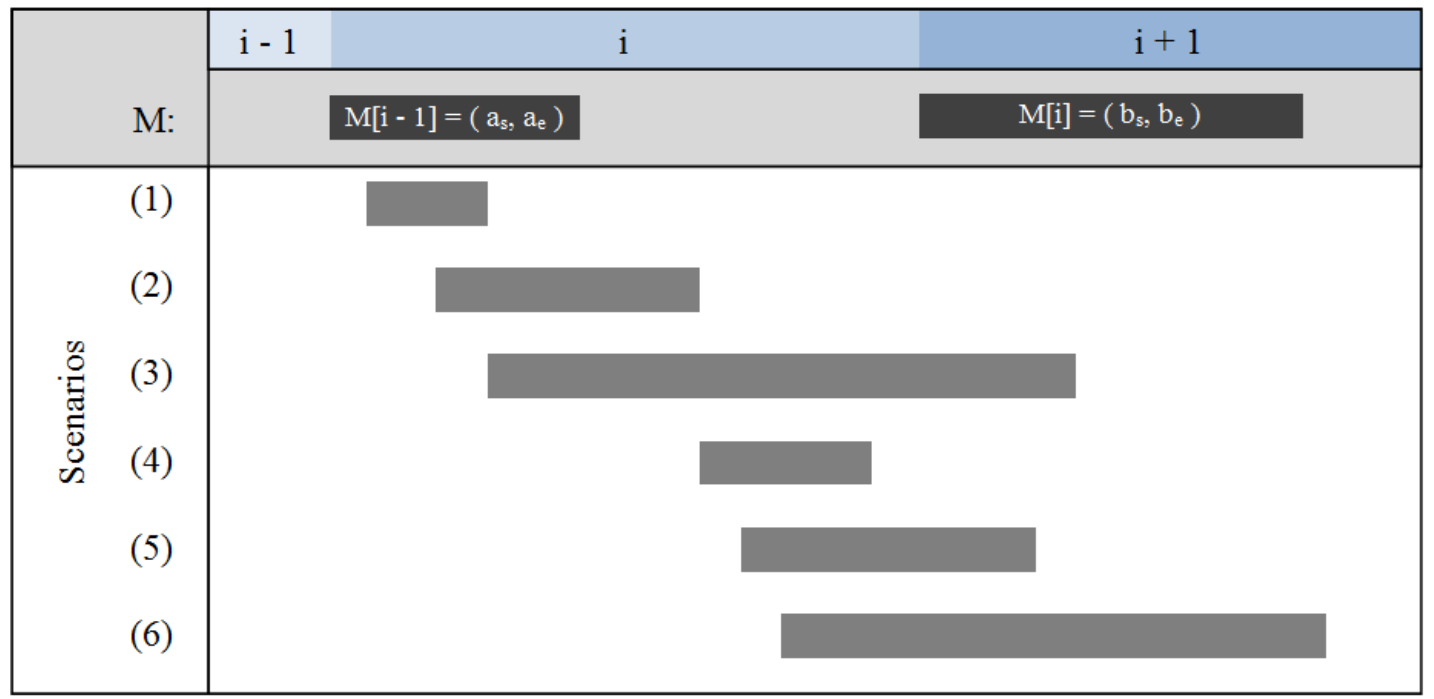

Figure 7. Scenarios for Memory Efficient Algorithm.

For any given index, i, one of six scenarios arises that the algorithm has to consider. Depending on the scenario, the algorithm has to decide how to alter the current set of ranges, $\mathrm{M}$, in order to account for the newest read. 


\subsection{3: Identify Quiescent Regions -- Speed Efficient Algorithm}

While the algorithm described above is memory efficient since it only keeps the minimum information necessary to identify the locations of the quiescent regions, it has a very slow execution speed and the logic inherent in the algorithm is highly complex and therefore prone to human error. Such slow speeds are most likely the result of the algorithm needing to find an index for each read to ensure the arrays stay in sorted order. This is a slow process since the size of the array grows as more information is processed. Also, every time a range is added or subtracted all the array indices must be adjusted up or down, respectively. This accounts for most of the CPU time that makes it so slow.

An additional algorithm was developed to try and fix these problems. The new method assigns each base in every contig or contiguous DNA segment a boolean value. The boolean value is 0 if the base has not been accounted for by a read and 1 if there has been at least one read aligned to that base. Each of these values are stored in an array (baseArray) can be used to determine where each of the quiescent regions are located. This algorithm is simple enough to describe using pseudocode (below). 
\# Determine Quiescent Regions

baseArray $=[0, \ldots, 0]$

Foreach( read in file)

For ( $i$ from start pos to end pos )

If ( baseArray [ $i$ ] equals 0 ) set baseArray[ $i$ ] to 1

\# Print Out Quiescent Regions

test $=-1$

Foreach( element in baseArray )

If ( test does not equal -1)

If ( baseArray [ $i$ ] equals 1 ) \{

set end $Q$ to $i$ - 1

print out "start $Q$ end $Q$ "

set test to -1

\}

go to next element in baseArray

If ( test equals -1 and baseArray[ $i$ ] equals 0 )

set start $Q$ to $i$

set test to 1 


\section{CHAPTER III}

\section{RESULTS}

\section{1: Chromosome Map}

After all the quiescent regions had been identified, a chromosome map was created to see where they are located and how they are distributed throughout the genome. Figure 8 shows this map. The map was created by combining data sets 1005 and F201. A Perl script was written to determine which regions were distinct to each of the data sets and which were common between the two. Each of the colored regions represents a quiescent region, where red represents data set 1005 only, green represents data set F201 only, and blue represents quiescent regions that the two data sets share. We found that approximately $20.45 \%$ (average of 1005 and F201) of the genome is transcriptionally quiescent.

Since the large RNA data sets (1005 and F201) have theoretically identical genomes with the exception of a single point mutation, it is not surprising that we see lots of overlapping regions (shown in Figure 8 in blue). Regions that the data sets do not share appear to be smaller in size. These differences are possibly the result of errors during the read sequencing. In general, the quiescent regions do not appear to follow a general pattern, but they do seem to be slightly more common near the ends of the chromosomes. 

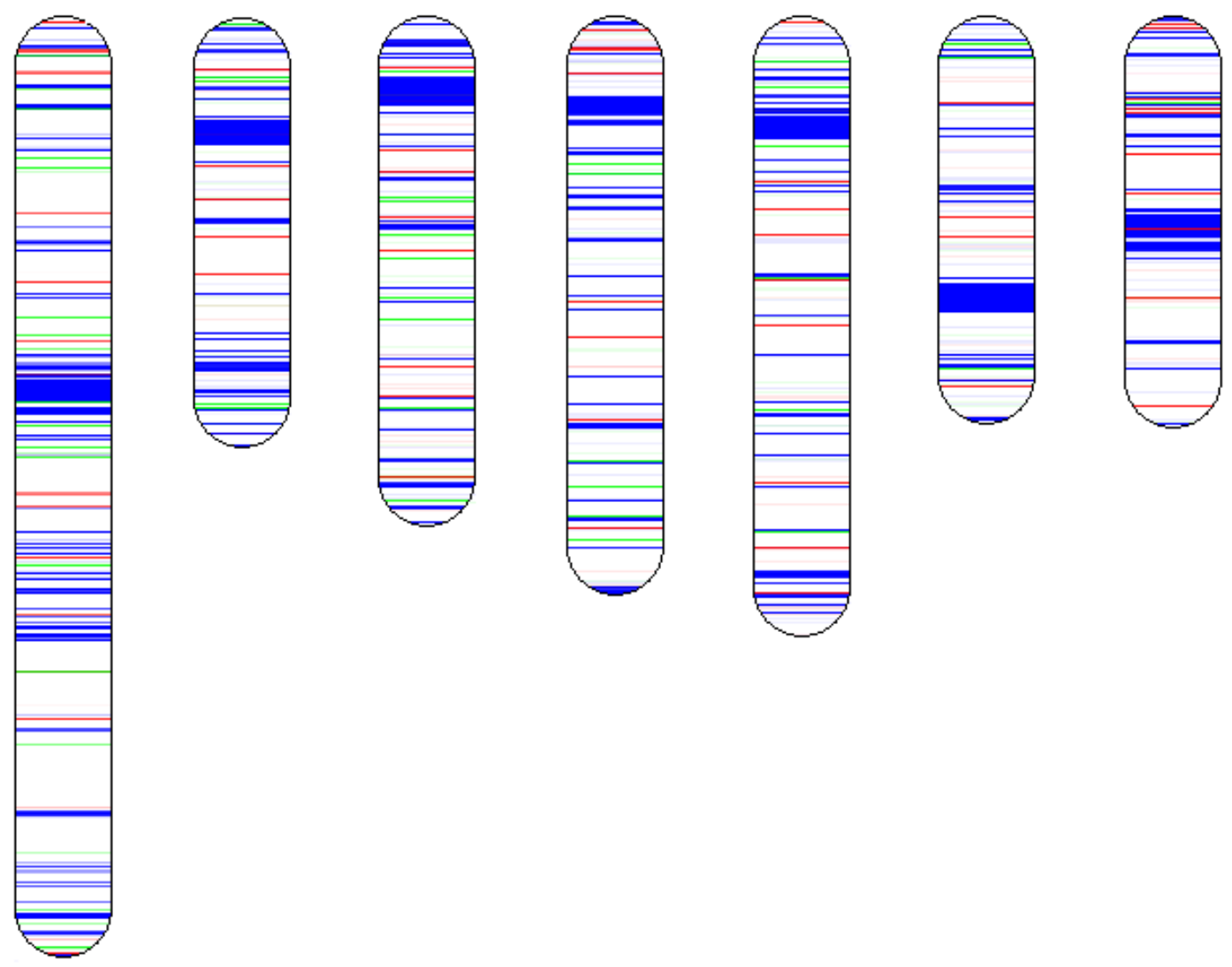

Figure 8. Chromosome Map for Combine Data Sets 1005 and F201.

The locations of the quiescent regions within the genome for the combined large RNA data sets (1005 and F201). Each colored region represents a quiescent region, where red represents data set 1005 only, green represents data set F201 only, and blue represents quiescent regions that the two data sets share. It should be noted that small regions will not show up due to the pixel limitations of the screen. Similarly, not all continuously solid colored regions are quiescent throughout. There may be small areas of transcription hidden within them. The program used for drawing the chromosome map was written in $\mathrm{C}++$ by Dan Souther.

\section{2: Analysis of Largest Quiescent Regions}

BLAST (Basic local alignment search tool) compares a query sequence to a database of other previously published sequences to give insight about its function or relationship to other sequences (Altschul et al. 1990). For each data set, the largest 35 
regions were BLASTed against NCBI's (National Center for Biotechnology Information) database to help speculate why these regions are transcriptionally quiescent.

A BLAST analysis reveals what is among the largest quiescent region in the $N$. crassa genome. The most common top hits were 'pol-like protein', ' hypothetical protein CHGG_08065', and 'hypothetical protein CHGG_10614'. These were the hits chosen to investigate further.

The 'pol-like protein' is related to a LINE-like retrotransposon in N. crassa called Tad (Cambareri et al. 1994). This transposon is active in N. crassa and capable of internuclear transfer. Among the most common classes, LINE-like transposable elements frequently appear in complex eukaryotes. Tad is one of the few transposable elements found to be active in the N. crassa genome (Cambareri et al. 1994).

Sequences that found hypothetical protein CHGG_08065 and hypothetical protein CHGG_10614 aligned to transposable elements found in other fungal and non-fungal genomes. In many cases these hypothetical proteins are thought to be reverse transcriptases responsible for the replication of retrotransposons and other mobile elements (Pérez-Alegre et al. 2005, DeMarco et al 2004, Kaneko et al. 2000). While they appear to be inactive in $N$. crassa, in some genomes these elements have high transcriptional activities (DeMarco et al. 2004).

By looking at the BLAST tables (Table 4 and 5), we can see that we have in fact indentified the centromeres on each chromosome as quiescent. Each of the centromere locations has been classified by Smith et al. 2011. In the BLAST tables for the large RNA data sets, values marked with a star $\left(^{*}\right)$ indicated regions that fall within the known 
centromere positions given by Table 3. Each chromosome's centromere was represented in the largest quiescent regions, except chromosome four and seven. It should be noted that chromosome four has the smallest sized centromere, which is possibly why it did not show up among the largest of the quiescent regions, but we still see it on the chromosome map.

Table 3. Centromere Locations.

Locations of each of the centromeres on each of the seven chromosomes found in $N$. crassa (Smith et al. 2011).

\begin{tabular}{|c|cccc|}
\hline Chromosome & Total Length & $\begin{array}{c}\text { Centromere } \\
\text { Position }\end{array}$ & $\begin{array}{c}\text { Centromere } \\
\text { Size }\end{array}$ & $\begin{array}{c}\text { Identified in Top } \\
\text { Quiescent Regions }\end{array}$ \\
\hline I & $9,798,893$ & $\begin{array}{r}3,736,000- \\
3,969,000\end{array}$ & 233,400 & Yes \\
\hline II & $4,478,683$ & $\begin{array}{r}1,105,000- \\
1,346,000\end{array}$ & 240,800 & Yes \\
\hline III & $5,274,802$ & $\begin{array}{r}705,000- \\
951,000\end{array}$ & 246,000 & Yes \\
\hline IV & $6,000,761$ & $\begin{array}{r}894,000- \\
1,068,000\end{array}$ & 174,000 & No \\
\hline V & 643,246 & $\begin{array}{r}932,000- \\
1,209,000\end{array}$ & 276,800 & Yes \\
\hline VI & $4,218,384$ & $\begin{array}{r}2,811,000- \\
3,060,000\end{array}$ & 249,000 & Yes \\
\hline VII & $4,255,303$ & $\begin{array}{r}1,801,000- \\
2,089,000\end{array}$ & 287,400 & No \\
\hline
\end{tabular}


Table 4. Top BLAST Results for Data Set 1005.

The top BLAST result from the 35 longest quiescent regions in the $N$. crassa genome according to data set 1005 .

\begin{tabular}{|c|c|c|c|c|c|c|}
\hline Contig & Start & End & Length & Top BLAST Result & E Value & Accession Number \\
\hline $12.6^{*}$ & 2843045 & 2913156 & 70112 & pol-like protein & 0 & AAA21792.1 \\
\hline $12.2 *$ & 1288997 & 1340422 & 51426 & pol-like protein & $9 \mathrm{E}-179$ & AAA21792.1 \\
\hline 12.1 & 877947 & 924534 & 46588 & hypothetical protein CHGG_10614 & 2E-110 & XP_001228541.1 \\
\hline 12.3 & 2192924 & 2236543 & 43620 & polymerase & $2 \mathrm{E}-170$ & AAK01619.1 \\
\hline 12.10 & 60458 & 98020 & 37563 & polymerase & $3 \mathrm{E}-146$ & AAK01619.1 \\
\hline 12.1 & 2295247 & 2331212 & 35966 & hypothetical protein CHGG_10614 & 0 & XP_001228541.1 \\
\hline 12.2 & 3663764 & 3699364 & 35601 & gag-pol polyprotein & $5 \mathrm{E}-128$ & ACD86393.1 \\
\hline 12.4 & 2345634 & 2378979 & 33346 & hypothetical protein SMAC_09651 & $1 \mathrm{E}-102$ & XP_003342462.1 \\
\hline 12.5 & 581326 & 614512 & 33187 & 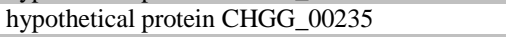 & $2 \mathrm{E}-82$ & XP_001219456.1 \\
\hline $12.5 *$ & 1033170 & 1066033 & 32864 & pol-like protein & $9 \mathrm{E}-160$ & AAA 21792.1 \\
\hline $12.3 *$ & 743348 & 773864 & 30517 & pol-like protein & 0 & AAA21792.1 \\
\hline 12.2 & 2123504 & 2153803 & 30300 & gag-pol polyprotein & 2E-90 & ACD86393.1 \\
\hline 12.5 & 4442662 & 4472366 & 29705 & hypothetical protein CHGG_10614 & 0 & XP_001228541.1 \\
\hline $12.2 *$ & 1094120 & 1123588 & 29469 & hypothetical protein CHGG_10614 & 0 & XP_001228541.1 \\
\hline 12.1 & 6385143 & 6414537 & 29395 & hypothetical protein CHGG_08065 & $6 \mathrm{E}-148$ & XP_001225721.1 \\
\hline 12.1 & 9481922 & 9511253 & 29332 & hypothetical protein CHGG_08065 & $4 \mathrm{E}-106$ & XP_001225721.1 \\
\hline 12.6 & 2992687 & 3021711 & 29025 & pol-like protein & 0 & AAA21792.1 \\
\hline 12.5 & 5659952 & 5688415 & 28464 & hypothetical protein CHGG_10614 & $1 \mathrm{E}-153$ & XP_001228541.1 \\
\hline 12.6 & 2787934 & 2816281 & 28348 & pol-like protein & 0 & AAA21792.1 \\
\hline $12.2 *$ & 1164034 & 1192055 & 28022 & pol-like protein & 0 & AAA21792.1 \\
\hline 12.6 & 4181257 & 4209127 & 27871 & hypothetical protein CHGG_10614 & $4 \mathrm{E}-164$ & XP_001228541.1 \\
\hline 12.4 & 5218762 & 5246454 & 27693 & hypothetical protein $\mathrm{CHGG} \_10614^{-}$ & 0 & XP_001228541.1 \\
\hline 12.4 & 3055027 & 3082226 & 27200 & hypothetical protein CHGG_08065 & 0 & XP_001225721.1 \\
\hline 12.10 & 98071 & 124249 & 26179 & hypothetical protein SMAC_09594 & $7 \mathrm{E}-100$ & XP_003343904.1 \\
\hline $12.1 *$ & 3792820 & 3818921 & 26102 & hypothetical protein, variant & 0 & ESĀ42110.1 \\
\hline 12.4 & 3743730 & 3769455 & 25726 & hypothetical protein CHGG_08792 & $3 \mathrm{E}-63$ & XP_001226719.1 \\
\hline 12.3 & 350934 & 376626 & 25693 & hypothetical protein SMAC_09651 & $6 \mathrm{E}-81$ & XP_003342462.1 \\
\hline $12.3 *$ & 932157 & 957687 & 25531 & pol-like protein & 0 & AAA21792.1 \\
\hline 12.5 & 2594135 & 2619307 & 25173 & polymerase & 0 & AAK01619.1 \\
\hline 12.7 & 3678169 & 3703281 & 25113 & hypothetical protein NEUTE2DRAFT_169926 & $5 \mathrm{E}-51$ & EGZ68151.1 \\
\hline 12.2 & 111618 & 136717 & 25100 & hypothetical protein CHGG_10614 & $1 \mathrm{E}-138$ & XP_001228541.1 \\
\hline 12.7 & 3406221 & 3431178 & 24958 & hypothetical protein SMAC_09594 & $2 \mathrm{E}-143$ & XP_003343904.1 \\
\hline 12.1 & 4169861 & 4194781 & 24921 & hypothetical protein $\mathrm{CHGG}_{-} 10614$ & $9 \mathrm{E}-117$ & XP_001228541.1 \\
\hline 12.4 & 1126474 & 1150552 & 24079 & hypothetical protein CHGG_10614 & 0 & XP_001228541.1 \\
\hline 12.1 & 5920134 & 5944188 & 24055 & hypothetical protein NEUTE-2DRAFT_169926 & $2 \mathrm{E}-32$ & EGZ̄68151.1 \\
\hline
\end{tabular}


Table 5. Top BLAST Results for Data Set F201.

The top BLAST result from the 35 longest quiescent regions in the N. crassa genome according to data set F201.

\begin{tabular}{|c|c|c|c|c|c|c|}
\hline Contig & Start & End & Length & Top BLAST Result & E Value & Accession Number \\
\hline $12.6^{*}$ & 2835356 & 2866221 & 30866 & pol-like protein & $7 \mathrm{E}-163$ & AAA21792.1 \\
\hline 12.10 & 80009 & 109358 & 29350 & putative retrotransposon nucleocapsid protein & $1.00 \mathrm{E}-114$ & EMR88181.1 \\
\hline 12.4 & 1881482 & 1910463 & 28982 & hypothetical protein CHGG_10614 & 0 & XP_001228541.1 \\
\hline 12.4 & 5218614 & 5246451 & 27838 & hypothetical protein CHGG_10614 & 0 & XP_001228541.1 \\
\hline 12.4 & 5969351 & 5996397 & 27047 & hypothetical protein CHGG_08288 & $2 \mathrm{E}-44$ & XP_001225944.1 \\
\hline 12.7 & 2248012 & 2274723 & 26712 & hypothetical protein SMAC_09594 & $5 \mathrm{E}-161$ & XP_003343904.1 \\
\hline $12.5 *$ & 1021689 & 1047668 & 25980 & hypothetical protein, variant & $1.00 \mathrm{E}-168$ & ESA-42110.1 \\
\hline 12.4 & 3743737 & 3769558 & 25822 & hypothetical protein CHGG_08792 & $3.00 \mathrm{E}-63$ & XP_001226719.1 \\
\hline 12.1 & 6428798 & 6454471 & 25674 & polymerase & $7.00 \mathrm{E}-164$ & AAK 01619.1 \\
\hline 12.1 & 9481998 & 9507656 & 25659 & hypothetical protein CHGG_08065 & $4.00 \mathrm{E}-106$ & XP_001225721.1 \\
\hline 12.2 & 2118897 & 2143472 & 24576 & hypothetical protein CHGG_02381 & $2.00 \mathrm{E}-64$ & XP_001228897.1 \\
\hline 12.1 & 5920169 & 5944131 & 23963 & hypothetical protein NEUTË2DRAFT_169926 & $2.00 \mathrm{E}-32$ & EGZ̄68151.1 \\
\hline 12.5 & 5659960 & 5683728 & 23769 & hypothetical protein CHGG_10614 & 9E-154 & XP_001228541.1 \\
\hline $12.1 *$ & 3792803 & 3816294 & 23492 & hypothetical protein, variant & 0 & ESĀ42110.1 \\
\hline 12.1 & 6385143 & 6408213 & 23071 & hypothetical protein CHGG_08065 & 4.00E-148 & XP_001225721.1 \\
\hline 12.5 & 591727 & 614523 & 22797 & hypothetical protein CHGG_00235 & $1.00 \mathrm{E}-82$ & XP_001219456.1 \\
\hline 12.7 & 2142674 & 2165318 & 22645 & hypothetical protein SMAC_09651 & 4E-90 & XP_003342462.1 \\
\hline 12.7 & 2216640 & 2238710 & 22071 & hypothetical protein SMAC_09651 & $2 \mathrm{E}-116$ & XP_003342462.1 \\
\hline 12.3 & 1252653 & 1274085 & 21433 & hypothetical protein NEUTE-1DRAFT_112574 & $1.00 \mathrm{E}-18$ & EGO54005.1 \\
\hline 12.1 & 9777606 & 9798700 & 21095 & hypothetical protein SMAC_09594 & $3.00 \mathrm{E}-90$ & XP_003343904.1 \\
\hline 12.3 & 4074450 & 4095395 & 20946 & hypothetical protein NCU10906 & 0.009 & XP_001728026.1 \\
\hline $12.2 *$ & 1259337 & 1280022 & 20686 & hypothetical protein CHGG_08393 & $2.00 \mathrm{E}-56$ & XP_001226320.1 \\
\hline 12.1 & 8227340 & 8247725 & 20386 & hypothetical protein NCU04703 & $3.00 \mathrm{E}-36$ & EAĀ30998.3 \\
\hline 12.1 & 904503 & 924640 & 20138 & hypothetical protein CHGG_08065 & $2.00 \mathrm{E}-99$ & XP_001225721.1 \\
\hline 12.3 & 4256738 & 4276599 & 19862 & hypothetical protein NCU04703 & $6.00 \mathrm{E}-35$ & EAA30998.3 \\
\hline 12.7 & 1324187 & 1344028 & 19842 & hypothetical protein CHGG_08065 & $7.00 \mathrm{E}-104$ & XP_001225721.1 \\
\hline 12.5 & 4452868 & 4472371 & 19504 & hypothetical protein CHGG_10614 & 0 & XP_001228541.1 \\
\hline 12.3 & 1702684 & 1722126 & 19443 & hypothetical protein CHGG_10614 & 0 & XP_001228541.1 \\
\hline 12.5 & 5897059 & 5916495 & 19437 & hypothetical protein $\mathrm{CHGG}_{-} 10614$ & $9.00 \mathrm{E}-169$ & XP_001228541.1 \\
\hline 12.1 & 9736539 & 9755560 & 19022 & gag-pol polyprotein & $1.00 \mathrm{E}-70$ & ACD 86393.1 \\
\hline 12.1 & 4075895 & 4094838 & 18944 & gag-pol polyprotein & $2.00 \mathrm{E}-57$ & ACD86393.1 \\
\hline 12.2 & 3904890 & 3923740 & 18851 & hypothetical protein SMAC_00575 & $1.00 \mathrm{E}-41$ & XP_003352028.1 \\
\hline 12.7 & 3678160 & 3696954 & 18795 & hypothetical protein NEUTE_DRAFT_169926 & $4.00 \mathrm{E}-51$ & EGZ̄68151.1 \\
\hline 12.1 & 6299389 & 6318162 & 18774 & hypothetical protein NEUTE1DRAFT_98304 & $1.00 \mathrm{E}-41$ & EGO61164.1 \\
\hline 12.4 & 4641201 & 4659543 & 18343 & hypothetical protein NEUTE1DRAFT_112574 & $3.00 \mathrm{E}-47$ & EGO54005.1 \\
\hline
\end{tabular}


Table 6. Top BLAST Results for Data Set SRR751454.

The top BLAST result from the 35 longest quiescent regions in the $N$. crassa genome according to data set SRR751454.

\begin{tabular}{|c|c|c|c|c|c|c|}
\hline Contig & Start & End & Length & Top BLAST Result & E Value & Accession Number \\
\hline 12.7 & 1117525 & 1120940 & 3416 & hypothetical protein $\mathrm{NC} 02593$ & 0.00008 & EAA35760.2 \\
\hline 12.1 & 4187715 & 4190235 & 2521 & hypothetical protein CHGG_08065 & $5 \mathrm{E}-11$ & XP_001225721.1 \\
\hline 12.7 & 1271256 & 1273678 & 2423 & No significant similarity found & & \\
\hline 12.7 & 906720 & 909056 & 2337 & hypothetical protein NCU16630 & $2 \mathrm{E}-16$ & ESA43159.1 \\
\hline 12.5 & 192452 & 194581 & 2130 & No significant similarity found & & \\
\hline 12.1 & 7424339 & 7426439 & 2101 & No significant similarity found & & \\
\hline 12.1 & 922438 & 924505 & 2068 & No significant similarity found & & \\
\hline 12.1 & 3698085 & 3700141 & 2057 & hypothetical protein NCU05738 & 0.0002 & XP_962894.1 \\
\hline 12.4 & 1929397 & 1931453 & 2057 & No significant similarity found & & \\
\hline 12.3 & 2290744 & 2292755 & 2012 & hypothetical protein CHGG_04034 & $4 \mathrm{E}-25$ & XP_001223248.1 \\
\hline 12.1 & 8285026 & 8286976 & 1951 & hypothetical protein CHGG_04032 & 0.0006 & XP_001223246.1 \\
\hline 12.3 & 1703106 & 1704988 & 1883 & No significant similarity found & & \\
\hline 12.4 & 2026841 & 2028719 & 1879 & Uncharacterized protein FFUJ 02954 & $3 \mathrm{E}-31$ & ССТ65963.1 \\
\hline 12.3 & 434434 & 436308 & 1875 & No significant similarity found & & \\
\hline 12.5 & 5709814 & 5711657 & 1844 & Uncharacterized protein FFUJ 02954 & $5 \mathrm{E}-28$ & ССТ65963.1 \\
\hline 12.7 & 1281123 & 1282924 & 1802 & No significant similarity found & & \\
\hline 12.4 & 440594 & 442369 & 1776 & No significant similarity found & & \\
\hline 12.5 & 178415 & 180140 & 1726 & No significant similarity found & & \\
\hline 12.1 & 3482653 & 3484370 & 1718 & hypothetical protein CHGG_10614 & $1 \mathrm{E}-12$ & XP_001228541.1 \\
\hline 12.2 & 2906890 & 2908598 & 1709 & polymerase & $1 \mathrm{E}-32$ & AAK 01619.1 \\
\hline 12.6 & 3532761 & 3534463 & 1703 & No significant similarity found & & \\
\hline 12.1 & 5539518 & 5541219 & 1702 & No significant similarity found & & \\
\hline 12.7 & 3678401 & 3680101 & 1701 & No significant similarity found & & \\
\hline 12.4 & 4253084 & 4254763 & 1680 & No significant similarity found & & \\
\hline 12.5 & 2622180 & 2623859 & 1680 & No significant similarity found & & \\
\hline 12.6 & 1988691 & 1990317 & 1627 & predicted protein & $1 \mathrm{E}-25$ & XP_001219297.1 \\
\hline 12.5 & 4245440 & 4247060 & 1621 & No significant similarity found & & \\
\hline 12.6 & 3238617 & 3240230 & 1614 & hypothetical protein CHGG 00074 & 0.0004 & XP 001219295.1 \\
\hline 12.1 & 5956005 & 5957600 & 1596 & hypothetical protein FOXB_12797 & $1 \mathrm{E}-15$ & EGU76692.1 \\
\hline 12.5 & 5234556 & 5236150 & 1595 & No significant similarity found & & \\
\hline 12.6 & 2385076 & 2386660 & 1585 & hypothetical protein FOC4 g10013526 & $5 \mathrm{E}-11$ & EMT63306.1 \\
\hline 12.7 & 1335604 & 1337177 & 1574 & hypothetical protein CHGG 10614 & $7 \mathrm{E}-16$ & XP 001228541.1 \\
\hline 12.1 & 3747988 & 3749553 & 1566 & hypothetical protein FOXB_04429 & $3 \mathrm{E}-12$ & EGU85056.1 \\
\hline 12.1 & 890965 & 892523 & 1559 & hypothetical protein CHGG_08065 & $8 \mathrm{E}-16$ & XP_001225721.1 \\
\hline 12.1 & 3063531 & 3065087 & 1557 & hypothetical protein FOC4_g10004840 & 2E-19 & EMT68755.1 \\
\hline
\end{tabular}


Table 7. Top BLAST Results for Data Set SRR755946.

The top BLAST result from the 35 longest quiescent regions in the $N$. crassa genome according to data set SRR755946

\begin{tabular}{|c|c|c|c|c|c|c|}
\hline Contig & Start & End & Length & Top BLAST Result & E Value & Accession Number \\
\hline 12.5 & 192381 & 194584 & 2204 & No significant similarity found & & \\
\hline 12.1 & 3698115 & 3700139 & 2025 & hypothetical protein NCU05738 & $2.00 \mathrm{E}-04$ & XP_962894.1 \\
\hline 12.5 & 2204995 & 2206976 & 1982 & hypothetical protein FOXB_16638 & 0.14 & EGŪ72852.1 \\
\hline 12.4 & 446096 & 447980 & 1885 & No significant similarity found & & \\
\hline 12.5 & 6109704 & 6111539 & 1836 & hypothetical protein PDIG_52550 & 0.031 & EKV11112.1 \\
\hline 12.5 & 5232425 & 5234253 & 1829 & hypothetical protein CHGG_10614 & $9.00 \mathrm{E}-10$ & XP_001228541.1 \\
\hline 12.7 & 1271893 & 1273679 & 1787 & No significant similarity found & & \\
\hline 12.7 & 2153900 & 2155628 & 1729 & retrovirus polyprotein, putative & $1 \mathrm{E}-16$ & XP_002145610.1 \\
\hline 12.7 & 2204108 & 2205827 & 1720 & No significant similarity found & & \\
\hline 12.1 & 5395490 & 5397196 & 1707 & predicted protein & $4.00 \mathrm{E}-42$ & XP_001219297.1 \\
\hline 12.7 & 3700796 & 3702409 & 1614 & No significant similarity found & & \\
\hline 12.7 & 1119373 & 1120954 & 1582 & No significant similarity found & & \\
\hline 12.4 & 4482424 & 4483910 & 1487 & No significant similarity found & & \\
\hline 12.1 & 2384366 & 2385775 & 1410 & No significant similarity found & & \\
\hline 12.6 & 2827499 & 2828904 & 1406 & No significant similarity found & & \\
\hline 12.3 & 2882047 & 2883438 & 1392 & hypothetical protein CHGG_03501 & $4.00 \mathrm{E}-08$ & XP_001230017.1 \\
\hline 12.6 & 1905196 & 1906586 & 1391 & hypothetical protein CHGG_00074 & $7.00 \mathrm{E}-07$ & XP_001219295.1 \\
\hline 12.4 & 4277774 & 4279158 & 1385 & No significant similarity found & & \\
\hline 12.7 & 1269731 & 1271115 & 1385 & No significant similarity found & & \\
\hline 12.1 & 72579 & 73956 & 1378 & No significant similarity found & & \\
\hline 12.7 & 1017788 & 1019158 & 1371 & hypothetical protein SMAC_09594 & $4.00 \mathrm{E}-67$ & XP_003343904.1 \\
\hline 12.7 & 3679627 & 3680991 & 1365 & No significant similarity found & & \\
\hline 12.4 & 1910907 & 1912268 & 1362 & No significant similarity found & & \\
\hline 12.7 & 1281654 & 1283003 & 1350 & No significant similarity found & & \\
\hline 12.5 & 178860 & 180191 & 1332 & No significant similarity found & & \\
\hline 12.5 & 2618058 & 2619383 & 1326 & No significant similarity found & & \\
\hline 12.4 & 4769367 & 4770677 & 1311 & hypothetical protein CHGG_00074 & $3.00 \mathrm{E}-11$ & XP_001219295.1 \\
\hline 12.5 & 587701 & 589008 & 1308 & No significant similarity found & & \\
\hline 12.4 & 4254496 & 4255797 & 1302 & No significant similarity found & & \\
\hline 12.1 & 5956094 & 5957394 & 1301 & hypothetical protein FOXB_12797 & $6.00 \mathrm{E}-16$ & EGU76692.1 \\
\hline 12.3 & 1703527 & 1704821 & 1295 & No significant similarity found & & \\
\hline 12.6 & 3411349 & 3412589 & 1241 & hypothetical protein NEUTE2DRAFT_114192 & $2.00 \mathrm{E}-27$ & EGZ70959.1 \\
\hline 12.2 & 391164 & 392399 & 1236 & No significant similarity found & & \\
\hline 12.6 & 2819151 & 2820382 & 1232 & hypothetical protein NCU04255 & 0.26 & XP_961246.1 \\
\hline 12.4 & 451143 & 452369 & 1227 & No significant similarity found & & \\
\hline
\end{tabular}




\section{3: Quiescent Region Summary Statistics}

Summary statistics (see Table 8) about the size of the quiescent regions for each of the data sets were obtained using R. $75 \%$ of the quiescent region lengths fall below 130 given by the third quartile. Hence, most of the quiescent regions are very small, so the data on the size of the quiescent regions is highly right skewed. A similar situation is true for the small RNA data sets.

Table 8. Summary Statistics: Size of Quiescent Regions.

\begin{tabular}{|c|cccc|}
\hline Summary & \multicolumn{4}{|c|}{ Data Set } \\
\cline { 2 - 5 } Statistics & $\mathbf{1 0 0 5}$ & F201 & SRR751454 & SRR755946 \\
\hline Min & 1 & 1 & 1 & 1 \\
Q1 & 20 & 20 & 10 & 8 \\
Median & 52 & 53 & 25 & 21 \\
Q3 & 131 & 135 & 55 & 46 \\
Max & 70110 & 46520 & 3416 & 2204 \\
Mean & 366.1 & 344.4 & 46.24 & 37.91 \\
SD & 1959.793 & 1589.285 & 72.590 & 57.800 \\
\hline
\end{tabular}

A population proportion test was performed to check if there are differences in GC content in the quiescent regions $\left(\mathrm{p}_{1}\right)$ is significantly different than what is observed in the whole genome (p). Once the locations of the quiescent regions were determined, a Perl script was written to calculate the $\mathrm{A} / \mathrm{T} / \mathrm{G} / \mathrm{C}$ proportions. This test can be done using a single population proportion test with the following null and alternative hypotheses:

$$
\begin{aligned}
& \mathrm{H}_{0}: \mathrm{p}_{1}=\mathrm{p} \\
& \mathrm{H}_{\mathrm{A}}: \mathrm{p}_{1} \neq \mathrm{p}
\end{aligned}
$$


with test statistic,

$$
z=\frac{\widehat{p_{1}}-p}{\sqrt{\frac{p(1-p)}{n}}}
$$

Four tests were performed at significance level $\alpha=0.05$. For all four tests, we found a significant test statistic to reject the null hypothesis that the quiescent regions have the same GC content as the whole genome ( $\mathrm{P}<0.0001$ for all tests). Results for these tests are summarized in Table 9.

Table 9. Summary of Results from Hypothesis Test for Differences in GC Content. This table compares GC and AT content in all quiescent regions from each data set to the whole genome proportions. The resulting p-values make it clear that all data sets had significantly different proportions of AT and GC than the whole genome. Significance level used for these tests was $\alpha=0.05$.

\begin{tabular}{|c|ccccc|}
\hline \multirow{2}{*}{ Summary Statistics } & \multicolumn{5}{|c|}{ Data Sets } \\
\cline { 2 - 6 } & $\begin{array}{c}\text { Whole } \\
\text { Genome }(\mathrm{p})\end{array}$ & $\begin{array}{c}1005 \\
\left(\hat{p}_{1}\right)\end{array}$ & $\begin{array}{c}\text { F201 } \\
\left(\hat{p}_{1}\right)\end{array}$ & $\begin{array}{c}\text { SRR751454 } \\
\left(\hat{p}_{1}\right)\end{array}$ & $\begin{array}{c}\text { SRR755946 } \\
\left(\hat{p}_{1}\right)\end{array}$ \\
\hline \% GC & $48.25 \%$ & $33.12 \%$ & $33.13 \%$ & $45.19 \%$ & $44.67 \%$ \\
\% AT & $51.75 \%$ & $66.88 \%$ & $66.87 \%$ & $54.81 \%$ & $55.33 \%$ \\
$\begin{array}{c}\text { p-Value for GC } \\
\text { Differences }\end{array}$ & & $<.0001$ & $<.0001$ & $<.0001$ & $<.0001$ \\
$\begin{array}{c}\text { p-Value for AT } \\
\text { Differences }\end{array}$ & & $<.0001$ & $<.0001$ & $<.0001$ & $<.0001$ \\
\begin{tabular}{c} 
Critical Values, $\mathrm{z}_{.025}$ \\
\hline
\end{tabular} & & \pm 1.96 & \pm 1.96 & \pm 1.96 & \pm 1.96 \\
\hline
\end{tabular}

\section{4: Analysis of Algorithms}

Two scripts for determining the locations of the quiescent regions were written.

One was designed to be memory efficient, since we are dealing with whole genome sized data, while the other one was designed to be simpler to understand and more time efficient. 
Both of the scripts were profiled to reveal exactly where their strengths and weakness were. Two memory tests were performed, one with a medium sized data set and another with a small data set. The first test used chromosome 7 from data set 1005, which contained approximately 18 million lines. During this test, the memory efficient algorithm used 9,962 K of memory, whereas the speed efficient algorithm used almost $15 \mathrm{X}$ that $(152,980 \mathrm{~K})$. The second test used a much smaller data set from contig 9 of data set SRR751454, which contained approximately one million lines. The memory efficient algorithm peaked at 6,652 $\mathrm{K}$ executing 920,262,957 statements, whereas the speed efficient algorithm peaked at $10,628 \mathrm{~K}$ and only executed $9,990,142$ statements. We can see that as the size of the file gets smaller the difference between the memory required decreases.

We also found that this memory efficiency came with a high cost of speed. Speed efficiency was determined using a Perl profiling module called NYTProf. This module gives the total time it takes for a Perl script to run, and it also breaks down the time spent in each subroutine of the code. Profiling with the data from chromosome 7 did not finish due to hard drive limitations. This module stores information about the algorithm's profile on a per-line basis, which requires a lot of space.

Table 10. Memory Efficient Algorithm Times by Subroutine.

\begin{tabular}{|l|l|l|}
\hline Calls & Exclusive Time & Subroutine \\
\hline 1383871 & $633 \mathrm{~s}$ & findIndex \\
\hline 1383873 & $1.93 \mathrm{~s}$ & readline \\
\hline 5844 & $1310 \mathrm{~ms}$ & insertNewLine \\
\hline 10150 & $78.0 \mathrm{~ms}$ & checkOverlap \\
\hline 1 & $15.6 \mathrm{~ms}$ & writeOutput \\
\hline
\end{tabular}


Using the smaller data set (contig 9 from data set SRR751454) the memory efficient program took 30.26 minutes to run, whereas the speed efficient algorithm only took 50.5 seconds. This time difference increases as the data size set gets larger. In the speed efficient algorithm, almost all of the time was accounted for in reading in and writing out lines. This was not case in the memory efficient algorithm. Table 10 shows a breakdown of each of the subroutine calls and the amount of time spent in each one for the smaller data set (contig 9 from data set SRR751454). Now, we can see that finding the index for each of the reads is what slowed the algorithm down. Also, when we had to insert a new line, each of the indices for the currently stored set needed to all be adjusted accordingly to make sure the arrays stayed in sorted order.

Table 11. Time and Memory Efficiency of Algorithms. Description of time and memory efficiency in big $\mathrm{O}$ notation of the algorithms that were written to determine quiescent regions.

\begin{tabular}{|c|c|c|}
\hline Algorithm & Time & Memory \\
\hline Memory Efficient & $\begin{array}{c}\text { O(sizeArray } * \\
\text { numAdjustments })=\mathrm{O}\left(\mathrm{n}^{\wedge} 3\right)\end{array}$ & $\begin{array}{c}\mathrm{O}(\mathrm{min}(\text { numRanges to represent } \\
\text { non-QRegions }))\end{array}$ \\
\hline Time Efficient & $\begin{array}{c}\mathrm{O}(\text { numReads } * \text { sizeRead })= \\
\mathrm{O}\left(\mathrm{n}^{\wedge} 2\right)\end{array}$ & $\mathrm{O}($ lengthContig) \\
\hline
\end{tabular}

The time and memory efficiency of both algorithms is described in Table 11. Both algorithms were polynomial in terms of time. However, the time efficient algorithm is more efficient since $\mathrm{O}\left(\mathrm{n}^{\wedge} 2\right)<\mathrm{O}\left(\mathrm{n}^{\wedge} 3\right)$. The memory efficient algorithm is more memory efficient since min(numRanges to represent non-QRegions) $<<$ lengthContig. 


\section{CHAPTER IV}

\section{DISCUSSION}

\section{1: Hypotheses About Transcriptional Quiescence}

This section is intended to discuss possible hypotheses about why these regions are transcriptionally quiescent.

\subsection{1: Evolutionary Origins of the Quiescent Regions}

In general, many of the largest quiescent regions contained transposable elements or relics of transposable elements many times within their top BLAST results. This trend has been observed in several other works (Lewis et al. 2009, Selker et al. 2003, Rountree 2010). In $N$. crassa, RIP acts as a genomic defense mechanism by identifying duplicated sequences and introducing mutations within them. Locations where mutations have occurred are highly susceptible to silencing via methylation. Therefore, it is not surprising that we see mutated transposable elements within the quiescent regions of the genome (Galagan and Selker 2004).

Centromeric regions, like other transcriptionally quiescent regions, have been found to be largely comprised of duplicated transposable elements that have been heavily mutated by RIP (Smith et al. 2011). Additionally, some of these centromeric regions may contain predicted genes (Smith et al. 2011). This would explain why we do not see 
quiescent regions the entire size of the centromeres, and in some cases (chromosomes four and seven) they do not even show up as one of the largest regions.

\subsection{2: GC/AT Content}

A process called RIP (repeat induced point mutation) acts on duplicated sequences within DNA, such as transposable elements that insert themselves in the genome at multiple locations, by inducing C-to-T and G-to-A mutations (Kelly \& Aramayo 2007, Freitag et al 2002, Hood 2005). Such mutations make these sequences highly susceptible to methylation, which causes silencing (Galagan and Selker 2004). This process protects the native genome against foreign invaders (Singer et al. 1995).

One hypothesis is that these regions are quiescent because RIP changes GC/AT content. We tested this hypothesis statistically to see if GC (or AT) content in the quiescent regions $\left(\mathrm{p}_{1}\right)$ is significantly different than what is observed in the whole genome (p). We performed this test at significance level $\alpha=0.05$ for each of the data sets. There was a significant test statistic to reject the null hypothesis that the quiescent regions have the same GC content as the whole genome ( $\mathrm{P}<0.0001$ for all tests).

Therefore, since the quiescent regions have statistically significant differences in GC/AT content than the whole genome, it is reasonable to hypothesize that the quiescent regions are highly mutated by RIP in $N$. crassa. This suggests that these regions are relics of transposable elements that have been heavily mutated by RIP and are now inactive. 


\section{2: Memory Efficiency vs. Speed Efficiency}

Two algorithms were written to determine which regions of the $N$. crassa genome are quiescent. There are pros and cons to each one. The first one was written strictly to be memory efficient, which I had assumed would be a major issue given that we are dealing with genome sized data. Unfortunately, the memory efficiency came at the cost of speed. Running this script for all four data sets took two computers almost two weeks to complete the analysis. Such time requirements would decrease the burden of repeating the analysis with additional data sets. This time inefficiency was found to be caused by a few different things. Most notably, for each read in the input file the algorithm had to search for the index where that read belonged so that it could always remain in sorted order. Additionally, each time an element was added or subtracted from the array all of the indices following it needed to be adjusted.

A simpler algorithm was written to solve the time requirement issue. This that was less memory efficient, but faster and less prone to logic errors in writing the scripts. This algorithm was so time efficient that most of the total time was spent reading in and writing out lines, as opposed to processing the information. While this algorithm had a larger memory footprint, it was not so large as to prevent the program from running.

Therefore, when deciding which algorithm to use it is really only important to consider the hardware being used. I would recommend using the memory efficient algorithm when memory is an issue. Consider that the Neurospora genome contains 40 million bases. To run the whole genome at once would require approximately $5.35 \mathrm{~GB}$ of memory. This is possible on a relatively modern computer. However, this may not be 
realistic with the human genome, which contains over 3 billion bases. This translates to approximately $400 \mathrm{~GB}$ of memory.

One way to get around possible memory issues would be to split the genome into smaller pieces before performing the analysis. A logical way to do this would be to divide the data set into each of the contigs. This would make using a typical computer more plausible if we could decrease the memory footprint sufficiently. Another possibility would be to alter the memory efficient algorithm improve its speed. As it is now, there are several places where this could happen. For instance, simply changing how it checks for overlapping data could reduce its speed down to $\mathrm{O}\left(\mathrm{n}^{\wedge} 2\right)$. 


\section{CHAPTER V}

\section{CONCLUSIONS}

\section{1: Final Thoughts}

Identifying the quiescent regions of the genome is the first step towards being able to distinguish theoretical aRNA from other RNA molecules. Since there are no other RNA transcripts present in these regions, if we see RNA molecules when we unpair them for MSUD, it's likely that they will in fact be aRNA. This is important for the study of MSUD proteins and possibly those proteins involved in meiosis that are required for identifying chromosomes as homologous pairs.

Based on an analysis of the quiescent regions, we can speculate that these regions appear to be relics of transposable elements that are highly mutated by RIP. We also found that there was a higher AT than GC content in the quiescent regions than what was present in the whole genome. This also suggests that RIP is at work since it causes C-toT and G-to-A mutations.

\section{2: Future Research}

Based on results obtained from the current work, a natural extension of this is to ask how similar the quiescent regions are in terms of structure and methylation patterns. Preliminary work by Jamieson et al. (2013) on histone H3 lysine methylation 
(H3K27me3) shows that H3K27me3 covers $6.8 \%$ of the Neurospora genome. All of these regions were found to be transcriptionally silent (Jamieson et al. 2013). Since we have found all of the transcriptionally quiescent regions, it would be appropriate to see if they all follow a similar pattern.

Additionally, theoretically the two large RNA data sets differ by only one single point mutation that causes the process of RIP to be active. It would be interesting to compare gene expression levels throughout the genome. Regions that differ most may be involved in 'ripping' duplicated regions of the genome. 


\section{REFERENCES}

Alexander, W. G., Raju, N. B., Xiao, H., Hammond, T. M., Perdue, T. D., Metzenberg, R. L., .. \& Shiu, P. K. (2008). DCL-1 colocalizes with other components of the MSUD machinery and is required for silencing. Fungal Genetics and Biology, 45(5), 719-727.

Altschul, S. F., Gish, W., Miller, W., Myers, E. W., \& Lipman, D. J. (1990). Basic local alignment search tool. Journal of molecular biology, 215(3), 403-410.

Borkovich K.A., Alex L.A., Yarden O. et al. (2004). Lessons from the genome sequence of Neurospora crassa: tracing the path from genomic blueprint to multicellular organism. Microbiol Mol Biol Rev, 68: 1Y108.

Cambareri, E. B., Singer, M. J., \& Selker, E. U. (1991). Recurrence of repeat-induced point mutation (RIP) in Neurospora crassa. Genetics, 127(4), 699-710.

Cambareri, E. B., Helber, J., \& Kinsey, J. A. (1994). Tadl-1, an active LINE-like element of Neurospora crassa. Molecular and General Genetics MGG, 242(6), 658-665.

Catalanotto C., Pallotta M., ReFalo P. et al. (2004). Redundancy of the two dicer genes in transgene-induced posttranscriptional gene silencing in Neurospora crassa. Mol Cell Biol, 24:2536Y2545.

Davis, R. H. (2000). Neurospora: contributions of a model organism (p. 333). New York: Oxford University Press.

DeMarco, R., Kowaltowski, A. T., Machado, A. A., Soares, M. B., Gargioni, C., Kawano, T., ... \& Verjovski-Almeida, S. (2004). Saci-1,-2, and-3 and Perere, four novel retrotransposons with high transcriptional activities from the human parasite Schistosoma mansoni. Journal of virology, 78(6), 2967-2978.

Feschotte, C., Jiang, N., \& Wessler, S. R. (2002). Plant transposable elements: where genetics meets genomics. Nature Reviews Genetics, 3(5), 329-341.

Foss H.M., Roberts C.J., Claeys K.M., Selker, E.U. (1993). Abnormal chromosome behavior in Neurospora mutants defective in DNA methylation. Science,262, 1737-1741. 
Freitag, M., Williams, R. L., Kothe, G. O., \& Selker, E. U. (2002). A cytosine methyltransferase homologue is essential for repeat-induced point mutation in Neurospora crassa. Proceedings of the National Academy of Sciences, 99(13), 8802-8807.

Galagan J.E., Calvo S.E., Borkovich K.A. et al. (2003). The genome sequence of the filamentous fungus Neurospora crassa. Nature, 422: 859Y868.

Galagan, J. E., \& Selker, E. U. (2004). RIP: the evolutionary cost of genome defense. Trends in Genetics, 20(9), 417-423.

Hammond, T. M., Xiao, H., Boone, E. C., Decker, L. M., Lee, S. A., Perdue, T. D., ... \& Shiu, P. K. (2013). Novel proteins required for meiotic silencing by unpaired DNA and siRNA generation in Neurospora crassa. Genetics, 194(1), 91-100.

Hammond, T. M., Xiao, H., Boone, E. C., Perdue, T. D., Pukkila, P. J., \& Shiu, P. K. (2011). SAD-3, a putative helicase required for meiotic silencing by unpaired DNA, interacts with other components of the silencing machinery. G3: Genes, Genomes, Genetics, 1(5), 369-376.

Hood, M. E., Katawczik, M., \& Giraud, T. (2005). Repeat-induced point mutation and the population structure of transposable elements in Microbotryum violaceum. Genetics, 170(3), 1081-1089.

Jamieson, K., Rountree, M. R., Lewis, Z. A., Stajich, J. E., \& Selker, E. U. (2013). Regional control of histone H3 lysine 27 methylation in Neurospora. Proceedings of the National Academy of Sciences, 110(15), 6027-6032.

Kaneko, I., Tanaka, A., \& Tsuge, T. (2000). REAL, an LTR retrotransposon from the plant pathogenic fungus Alternaria alternata. Molecular and General Genetics $M G G, 263(4), 625-634$.

Kelly, W. G., \& Aramayo, R. (2007). Meiotic silencing and the epigenetics of sex. Chromosome research, 15(5), 633-651.

Langmead, B., Trapnell, C., Pop, M., \& Salzberg, S. L. (2009). Ultrafast and memoryefficient alignment of short DNA sequences to the human genome. Genome Biol, 10(3), R25.

Langmead, B., \& Salzberg, S. L. (2012). Fast gapped-read alignment with Bowtie 2. Nature methods, 9(4), 357-359.

Lee, D. W., Pratt, R. J., McLaughlin, M., \& Aramayo, R. (2003). An argonaute-like protein is required for meiotic silencing. Genetics, 164(2), 821. 
Lee, D. W., Millimaki, R., \& Aramayo, R. (2010). QIP, a component of the vegetative RNA silencing pathway, is essential for meiosis and suppresses meiotic silencing in Neurospora crassa. Genetics, 186(1), 127-133.

Lewis, Z. A., Honda, S., Khlafallah, T. K., Jeffress, J. K., Freitag, M., Mohn, F., ... \& Selker, E. U. (2009). Relics of repeat-induced point mutation direct heterochromatin formation in Neurospora crassa. Genome research, 19(3), 427437.

Li, H., Ruan, J., \& Durbin, R. (2008a). Mapping short DNA sequencing reads and calling variants using mapping quality scores. Genome research, 18(11), 1851-1858.

Li, H., Handsaker, B., Wysoker, A., Fennel, T., Ruan, J., Homer, N., ...\& Durbin, R. (2009). The sequence alignment/map format and SAMtools. Bioinformatics, 25(16), 2078-2079.

Li, R., Li, Y., Kristiansen, K., \& Wang, J. (2008b). SOAP: short oligonucleotide alignment program. Bioinformatics, 24(5), 713-714.

Lister, R., Pelizzola, M., Dowen, R. H., Hawkins, R. D., Hon, G., Tonti-Filippini, J., ... \& Ecker, J. R. (2009). Human DNA methylomes at base resolution show widespread epigenomic differences. Nature, 462(7271), 315-322.

Norris, Jeffery. (2013, February 13). "Gene Invaders Are Stymied by a Cell's Genome Defense." University of California, San Francisco. N.p., n.d.

Pérez-Alegre, M., Dubus, A., \& Fernández, E. (2005). REM1, a new type of long terminal repeat retrotransposon in Chlamydomonas reinhardtii. Molecular and cellular biology, 25(23), 10628-10638.

Pratt R.J., Lee D.W., Aramayo R. (2004). DNA methylation affects meiotic transsensing, not meiotic silencing, in Neurospora. Genetics, 168,1925-1935.

Rountree, M. R., \& Selker, E. U. (2010). DNA methylation and the formation of heterochromatin in Neurospora crassa. Heredity, 105(1), 38-44.

SAM Format Specification Working Group. The SAM format specification (v1. 4-r985).

Selker, E. U., Tountas, N. A., Cross, S. H., Margolin, B. S., Murphy, J. G., Bird, A. P., \& Freitag, M. (2003). The methylated component of the Neurospora crassa genome. Nature, 422(6934), 893-897.

Shiu P.K., Raju B.N., Zickler D., Metzenberg R. (2001). Meiotic silencing by unpaired DNA. Cell, 107: 905 Y916. 
Shiu, P. K., \& Metzenberg, R. L. (2002). Meiotic silencing by unpaired DNA: properties, regulation and suppression. Genetics, 161(4), 1483-1495.

Shiu, P. K., Zickler, D., Raju, N. B., Ruprich-Robert, G., \& Metzenberg, R. L. (2006). SAD-2 is required for meiotic silencing by unpaired DNA and perinuclear localization of SAD-1 RNA-directed RNA polymerase. Proceedings of the National Academy of Sciences of the United States of America, 103(7), 22432248.

Singer, M. J., Marcotte, B. A., \& Selker, E. U. (1995). DNA methylation associated with repeat-induced point mutation in Neurospora crassa. Molecular and cellular biology, 15(10), 5586-5597.

Slotkin, R. K., \& Martienssen, R. (2007). Transposable elements and the epigenetic regulation of the genome. Nature Reviews Genetics, 8(4), 272-285.

Smith, K. M., Phatale, P. A., Sullivan, C. M., Pomraning, K. R., \& Freitag, M. (2011). Heterochromatin is required for normal distribution of Neurospora crassa CenH3. Molecular and cellular biology, 31(12), 2528-2542.

Wang Z., Gerstein M., Snyder M. (2009). RNA-Seq: a revolutionary tool for transcriptomics. Nature Reviews Genetics, 10,57-63.

Xiao, H., Alexander, W. G., Hammond, T. M., Boone, E. C., Perdue, T. D., Pukkila, P. J., \& Shiu, P. K. (2010). QIP, a protein that converts duplex siRNA into single strands, is required for meiotic silencing by unpaired DNA. Genetics, 186(1), 119126. 


\section{APPENDIX}

\section{PERL SCRIPTS}

\section{Convert CIGAR Scores to Lengths}

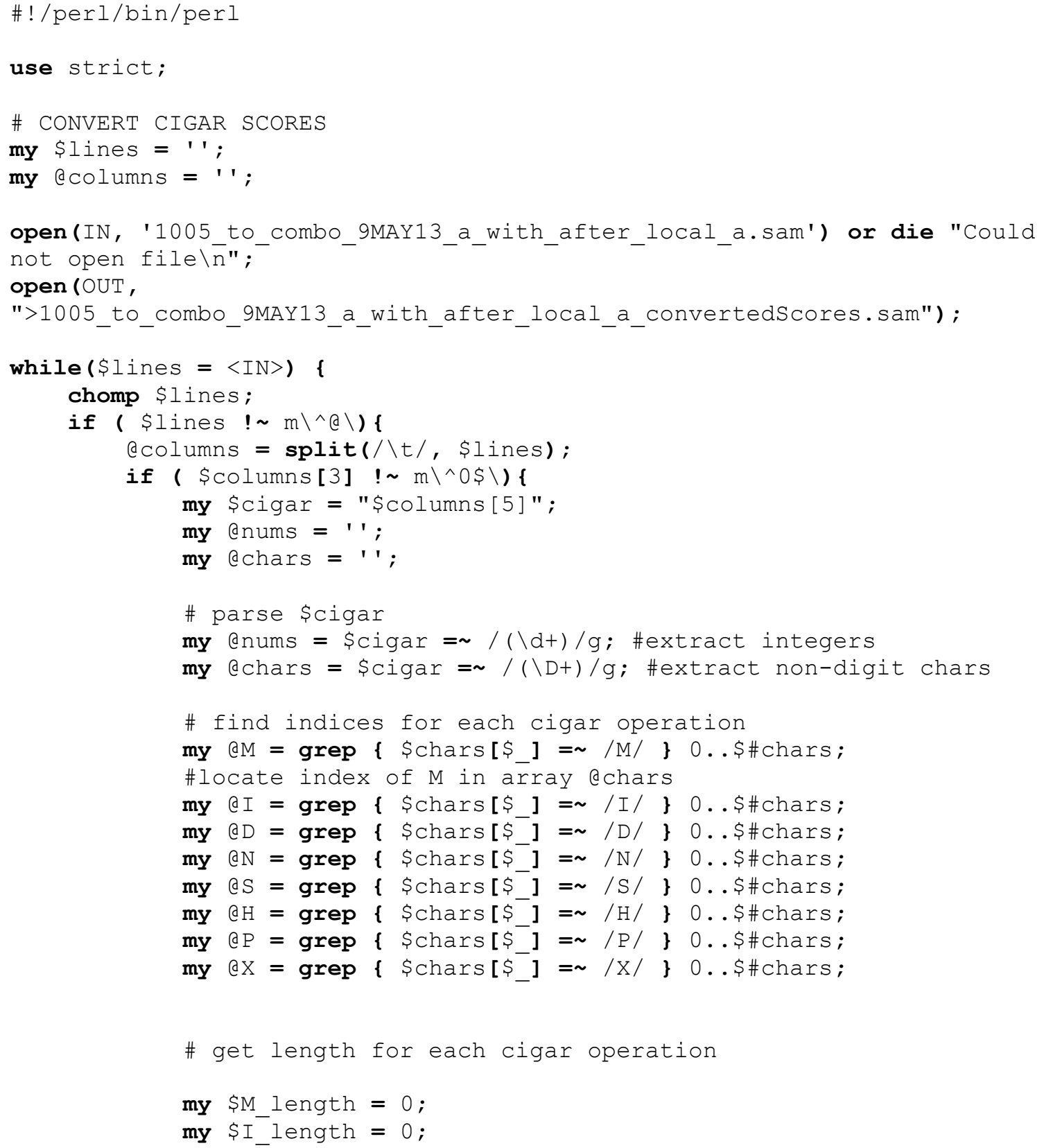




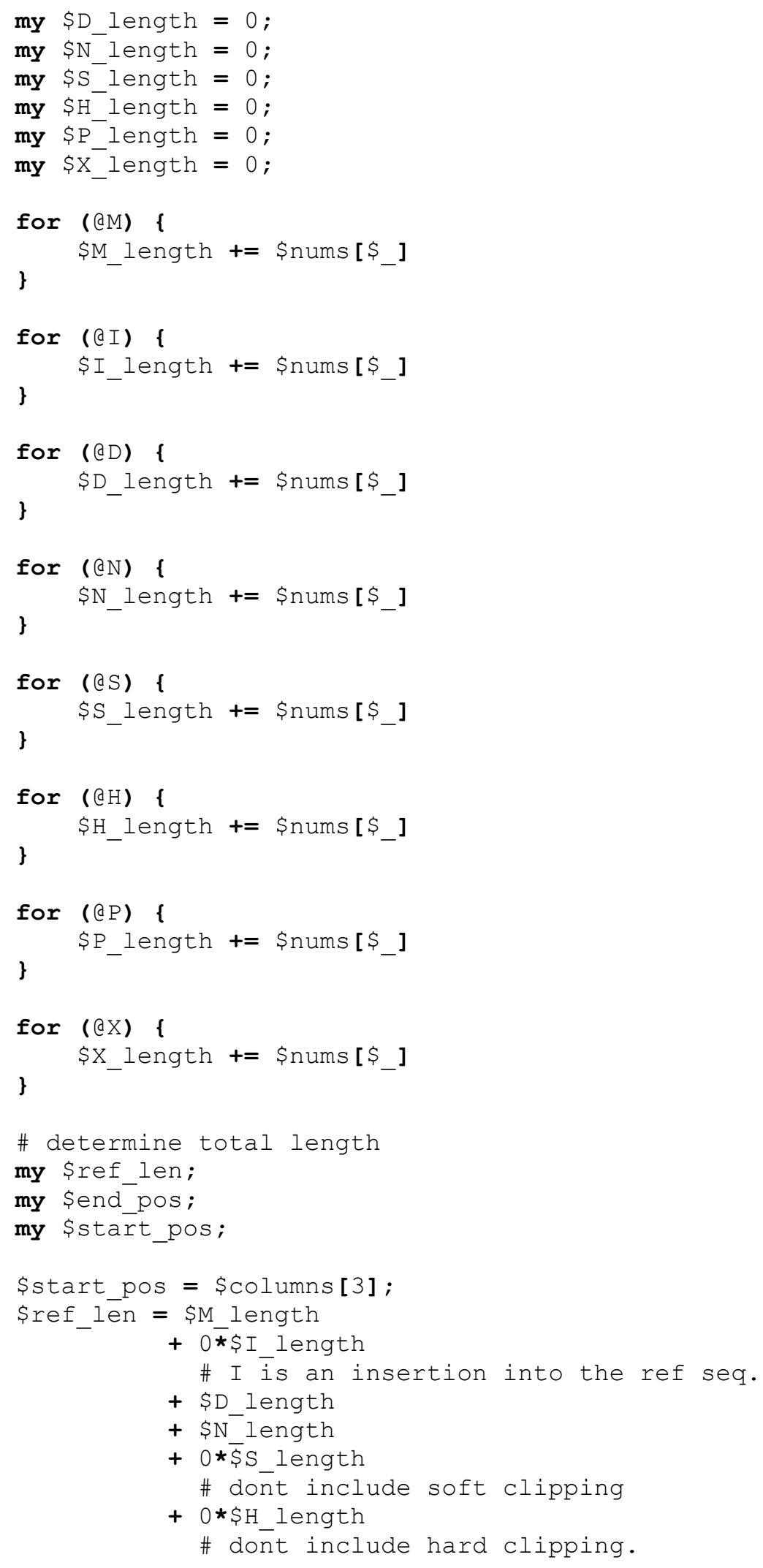




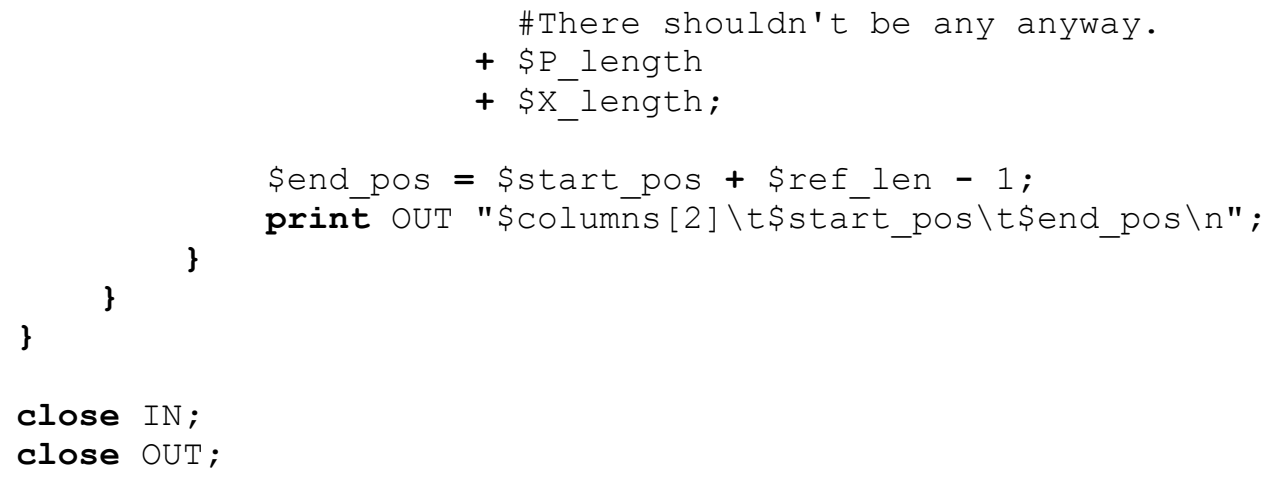

Sort By Contig

\#! /perl/bin/perl

use strict;

my \$lines;

my @columns;

for (my $\$ i=1 ; \$ i<21 ; \$ i=\$ i+1)\{$ 


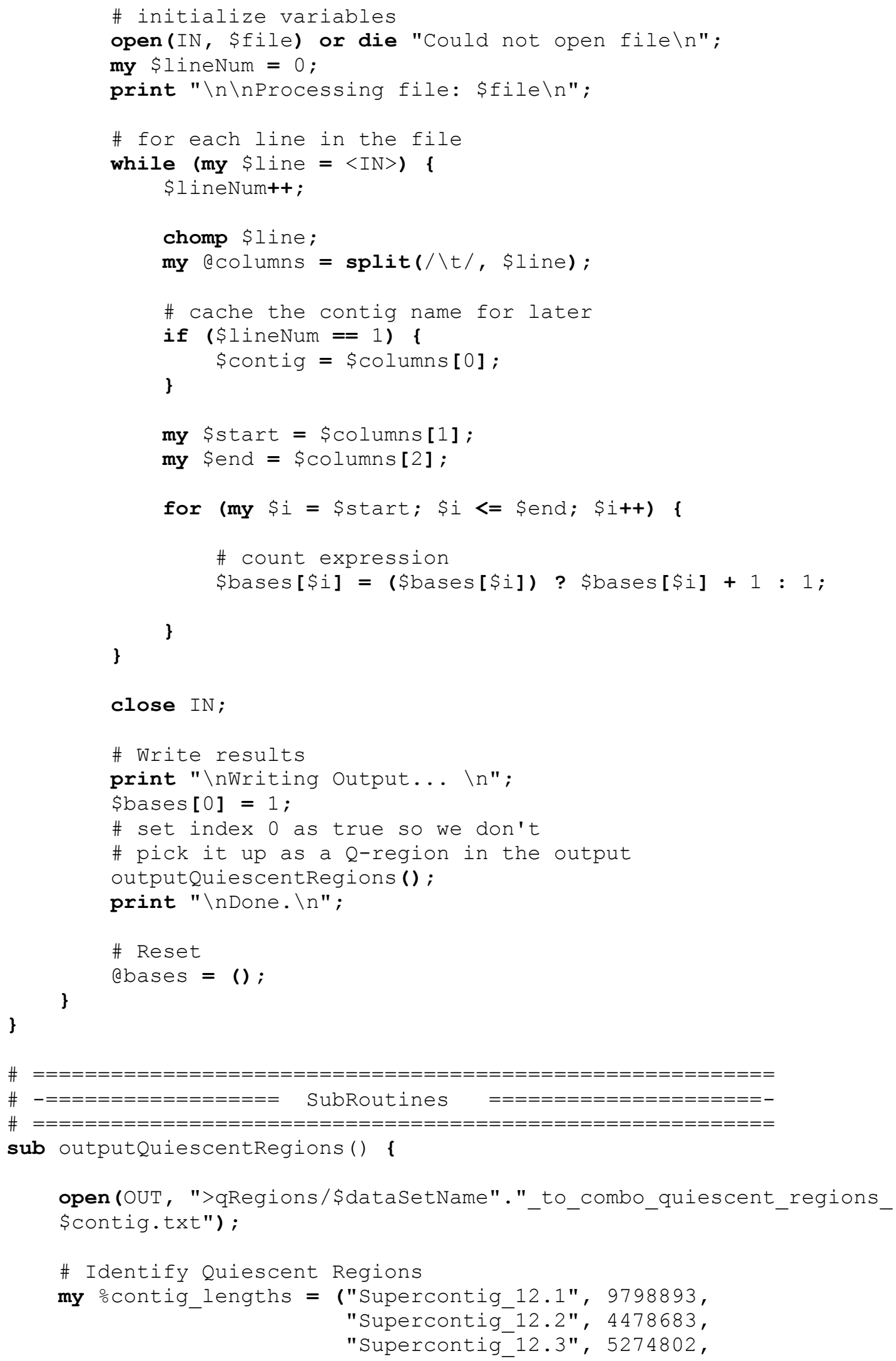


"Supercontig_12.4", 6000761 ,

"Supercontig 12.5", 6436246,

"Supercontig_12.6", 4218384,

"Supercontig_12.7", 4255303,

"Supercontig_12.8", 192308,

"Supercontig_12.9", 142473,

"Supercontig_12.10", 125404,

"Supercontig_12.11", 31696 ,

"Supercontig 12.12", 19714,

"Supercontig_12.13", 13515,

"Supercontig_12.14", 11565,

"Supercontig_12.15", 9397,

"Supercontig 12.16", 8983,

"Supercontig_12.17", 6701,

"Supercontig_12.18", 6309,

"Supercontig_12.19", 4755,

"Supercontig_12.20", 1646);

my \$start $=-1$;

my send = -1;

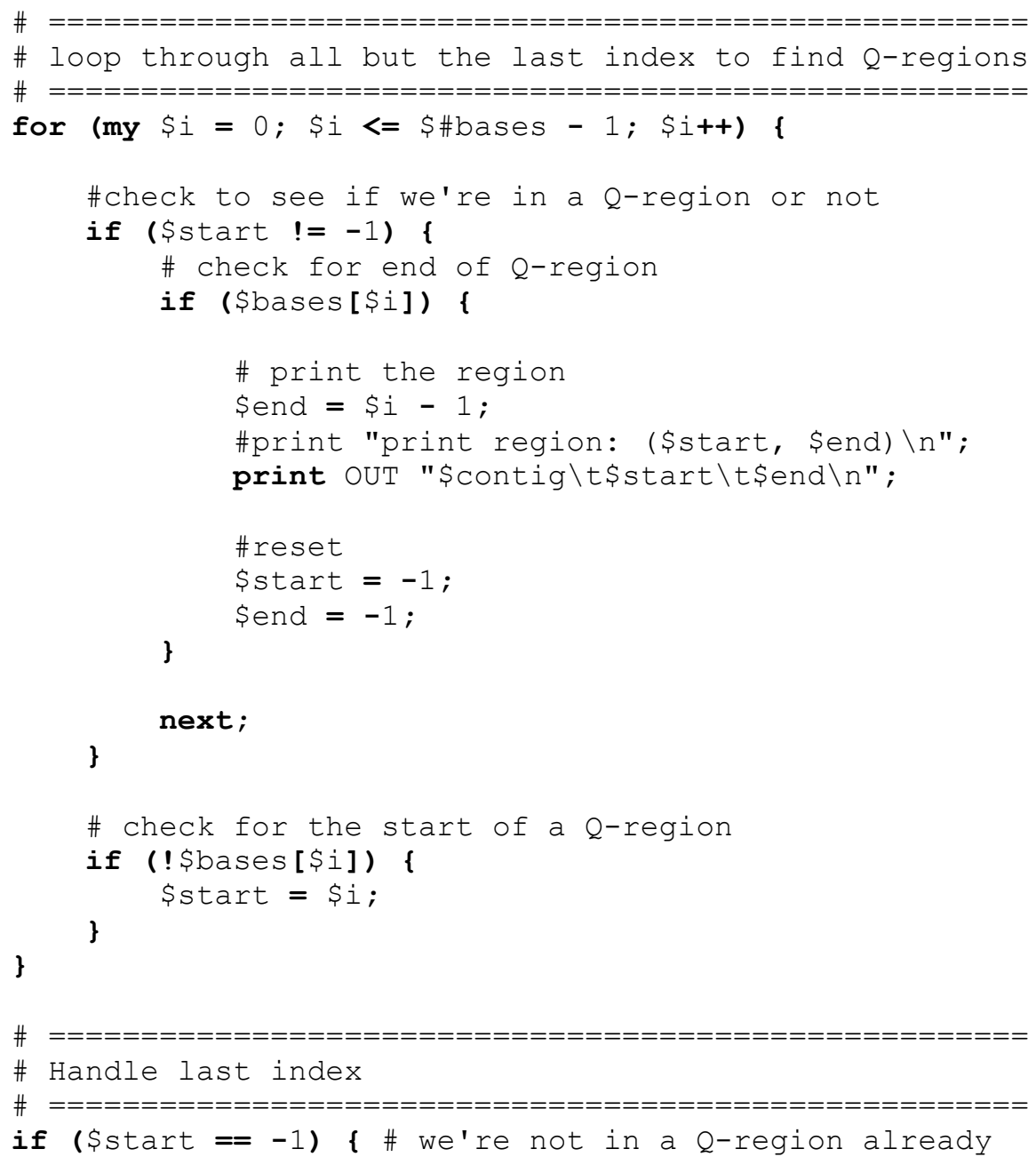




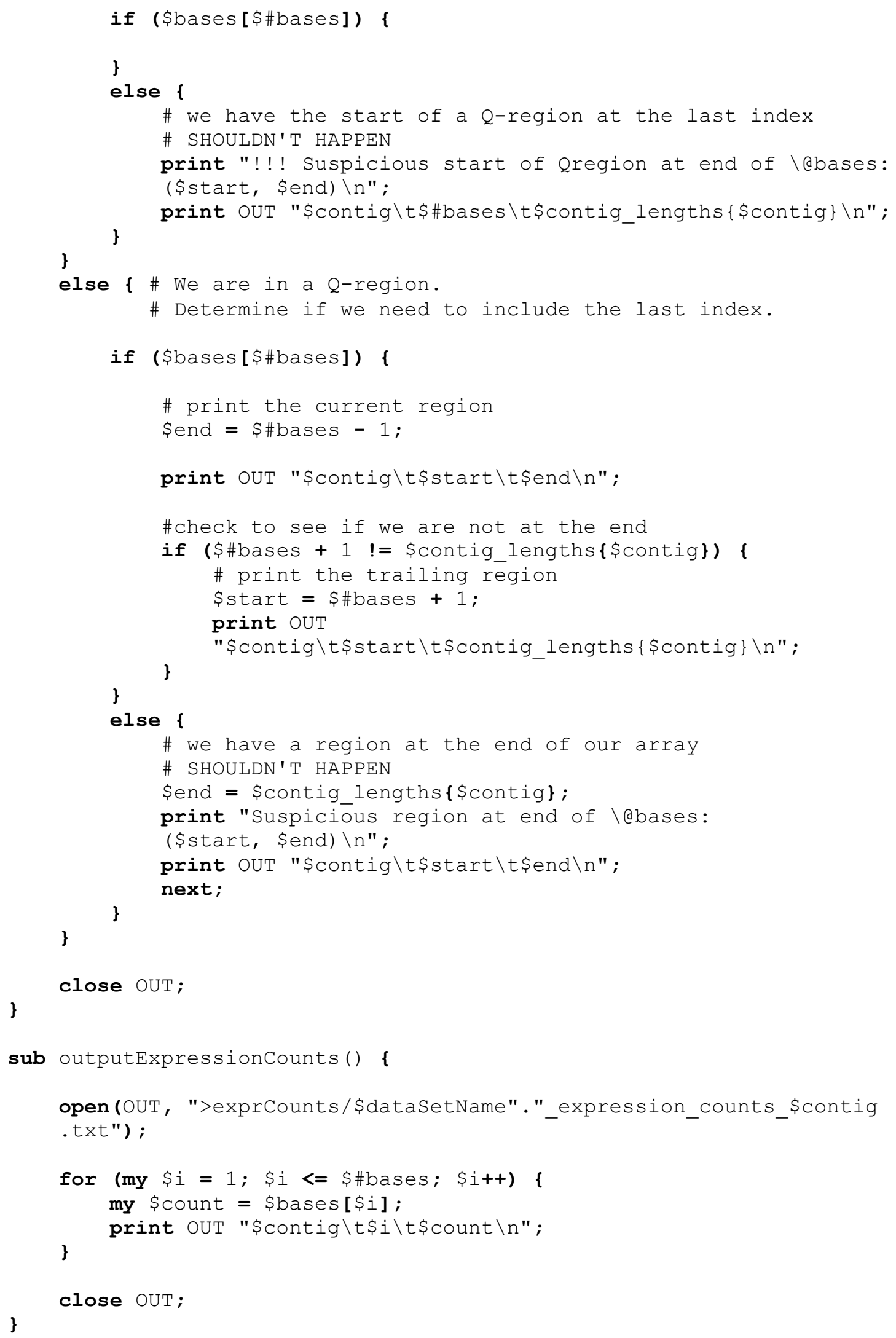




\section{Memory Efficient Algorithm}

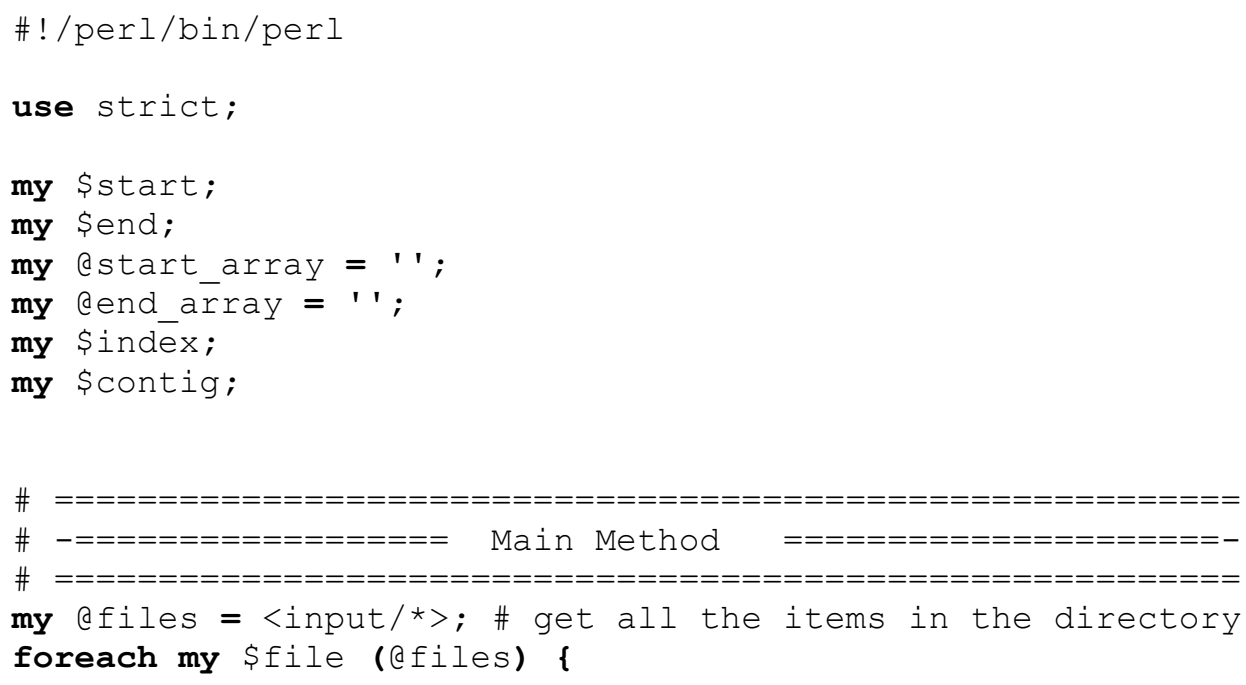




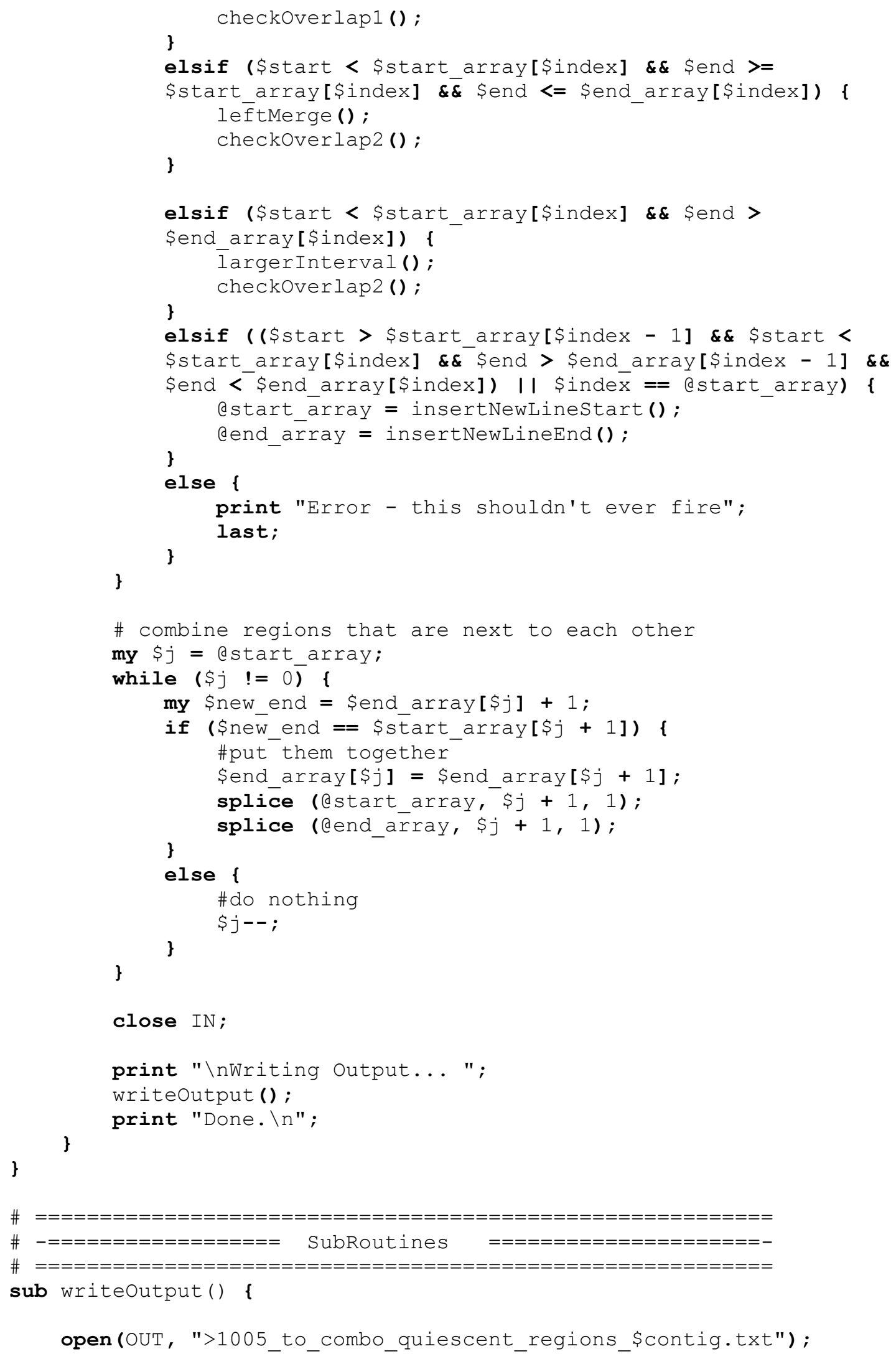




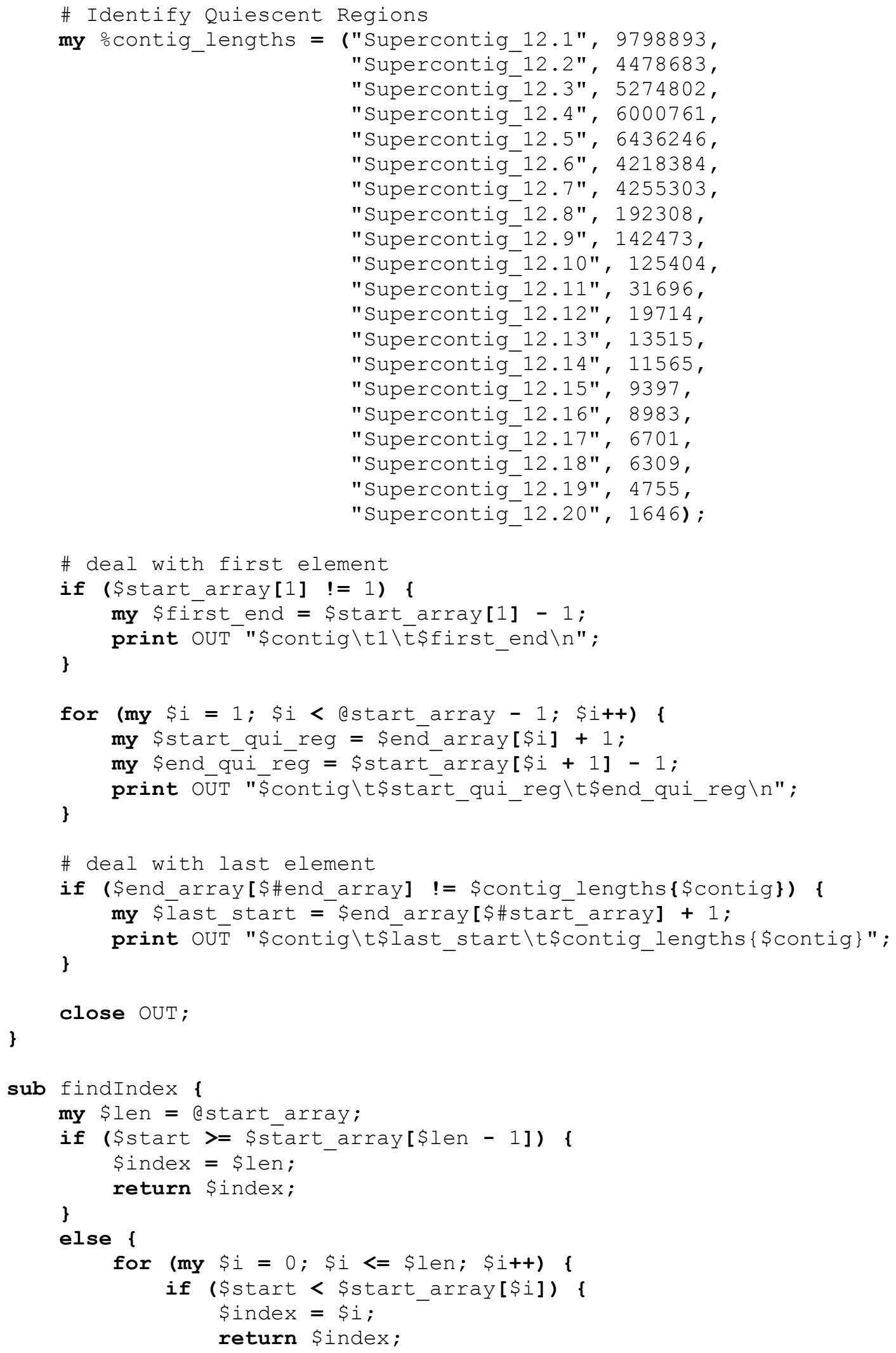




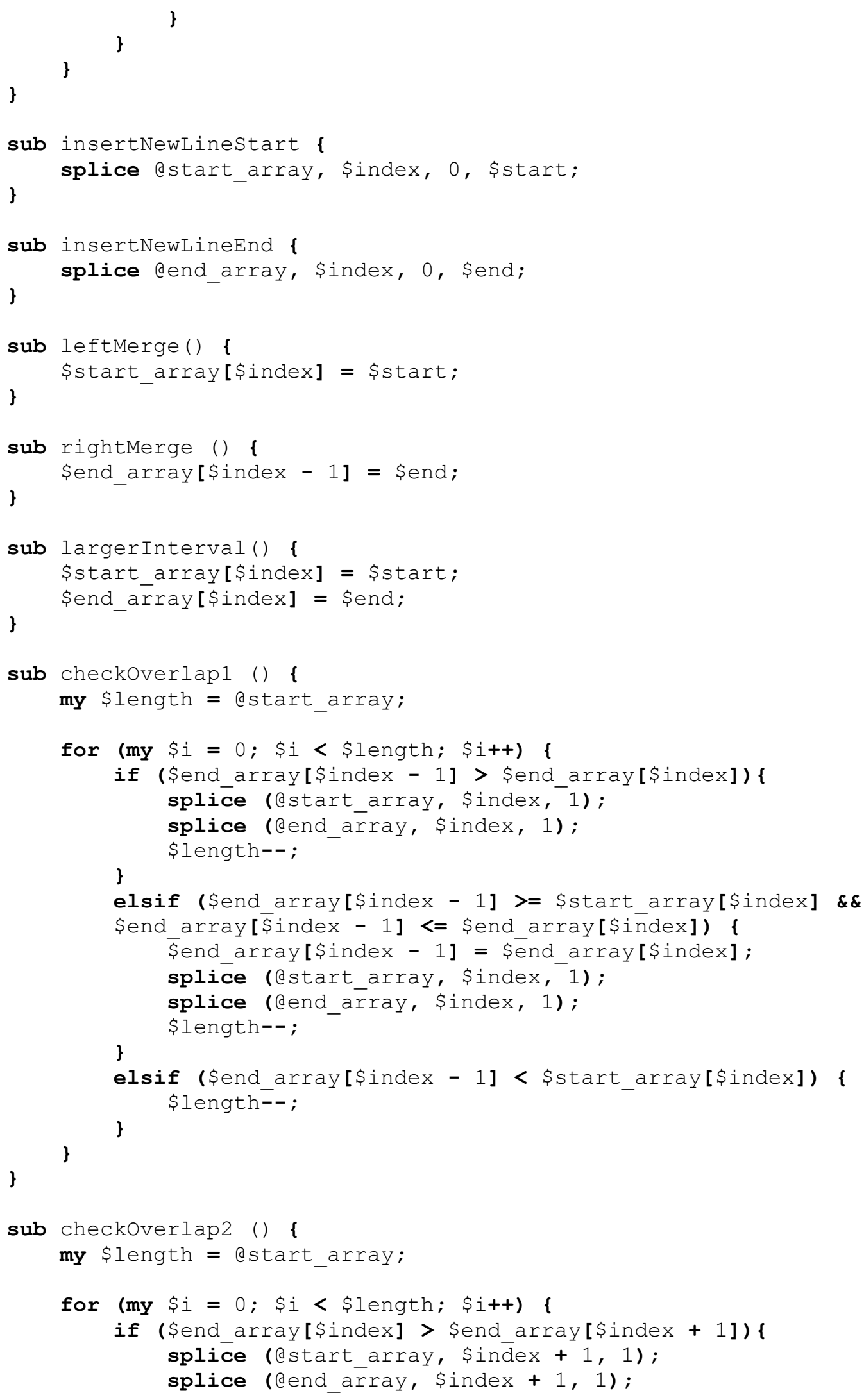




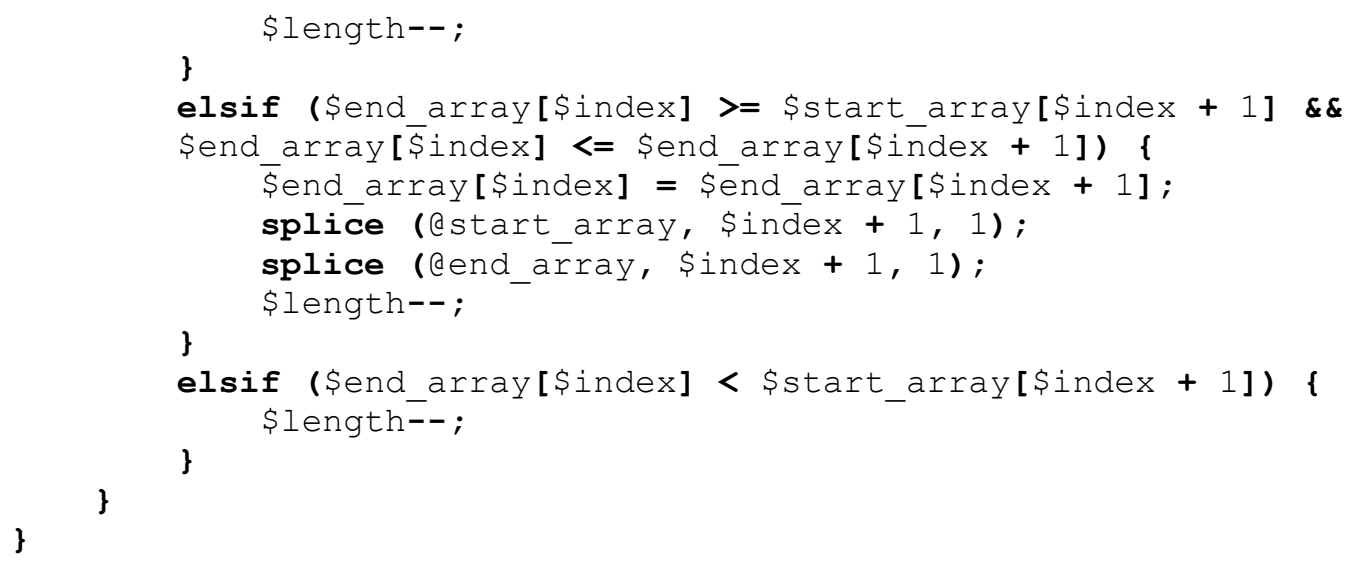

\section{Find the 35 Largest Quiescent Regions}

\#! /perl/bin/perl

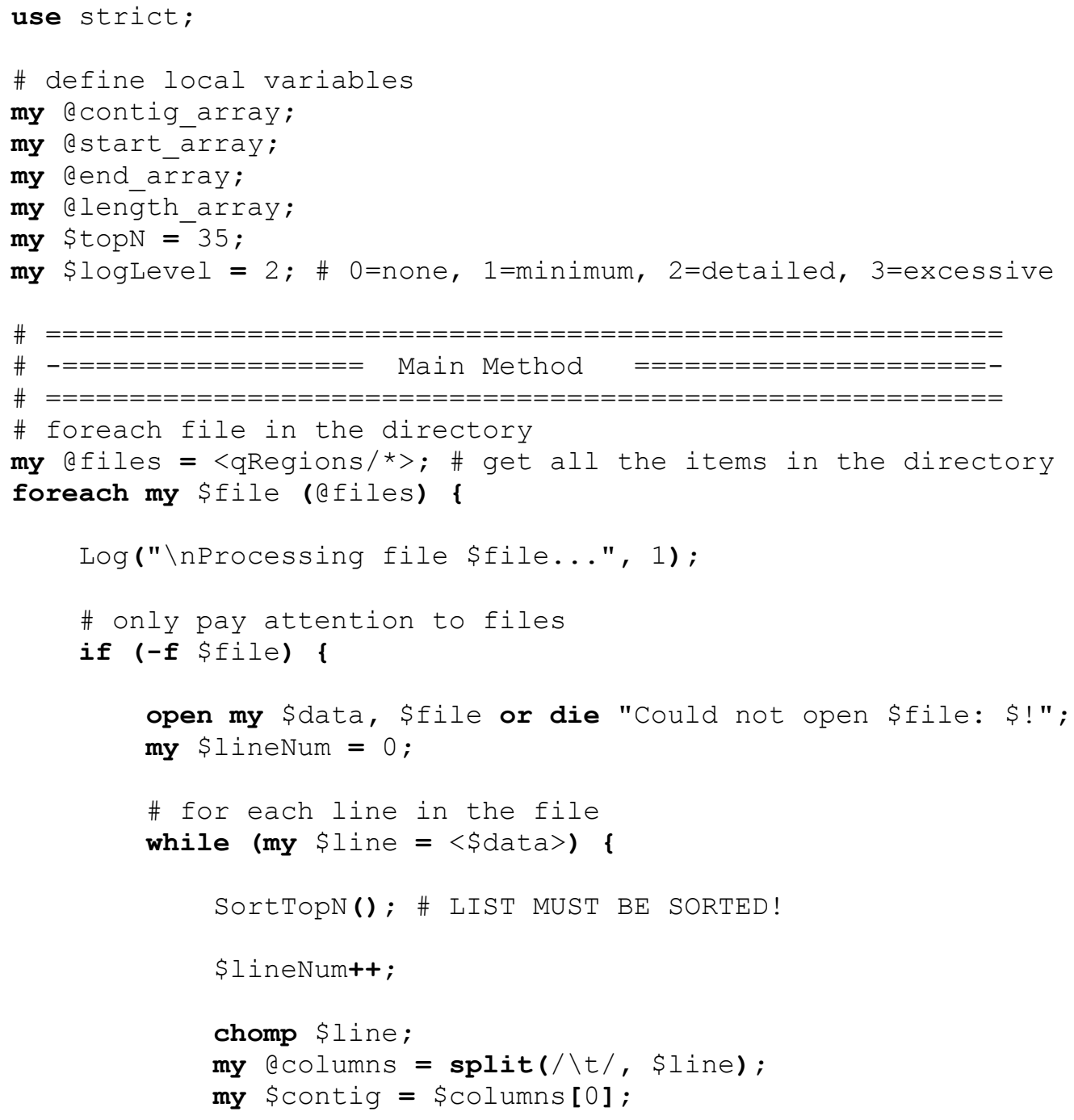




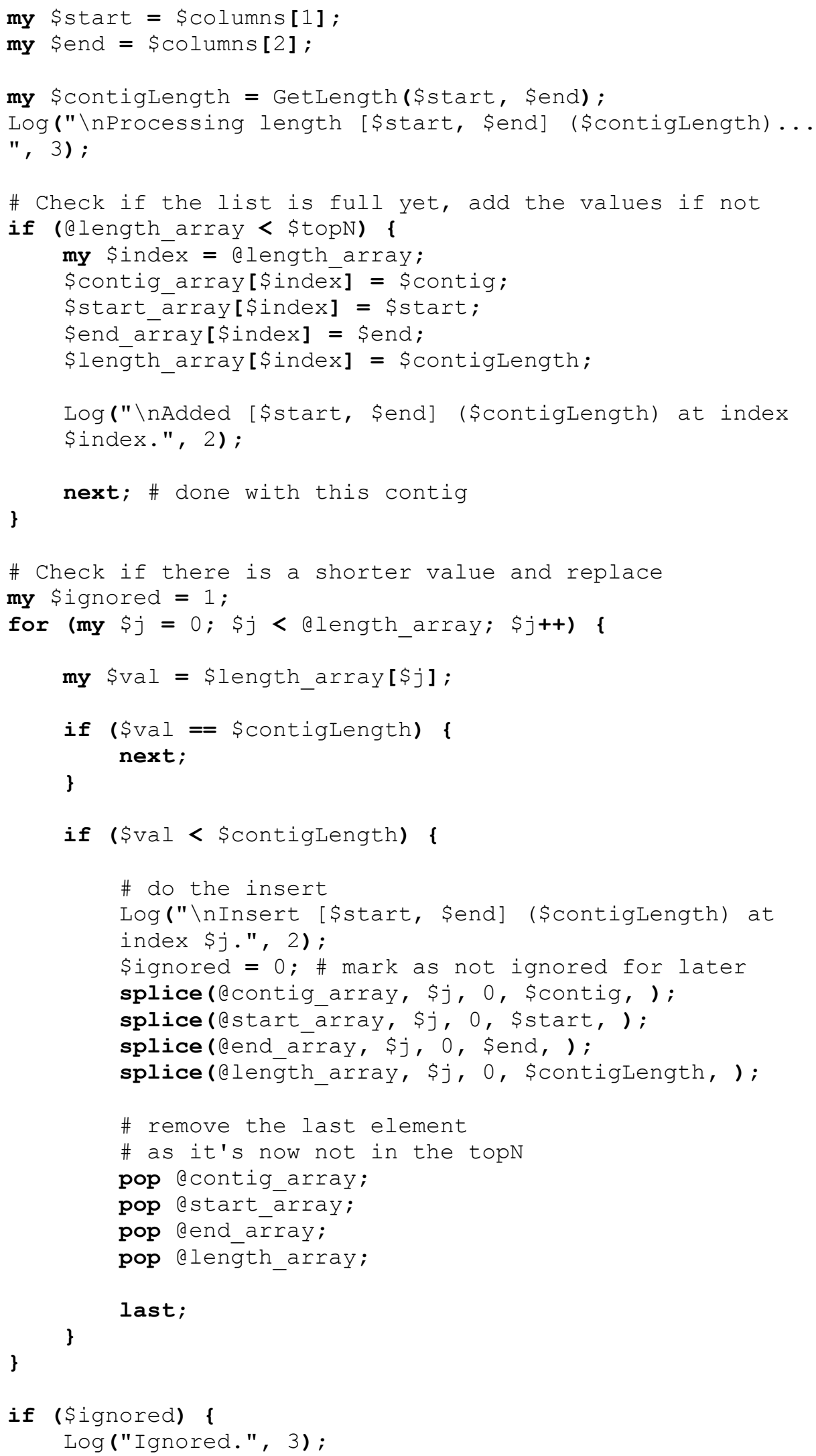




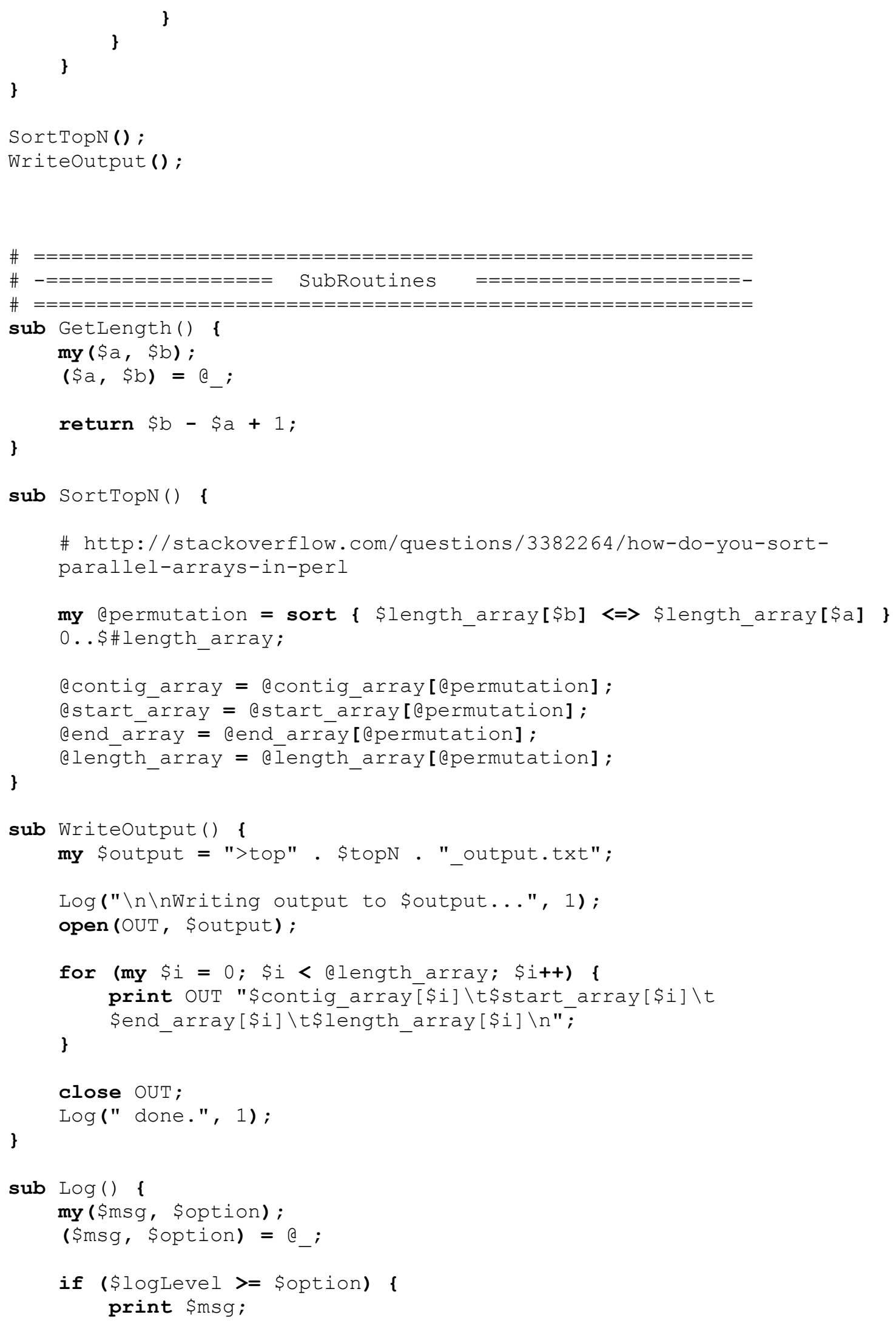




\section{Determine A/T/G/C Content in Whole Genome}

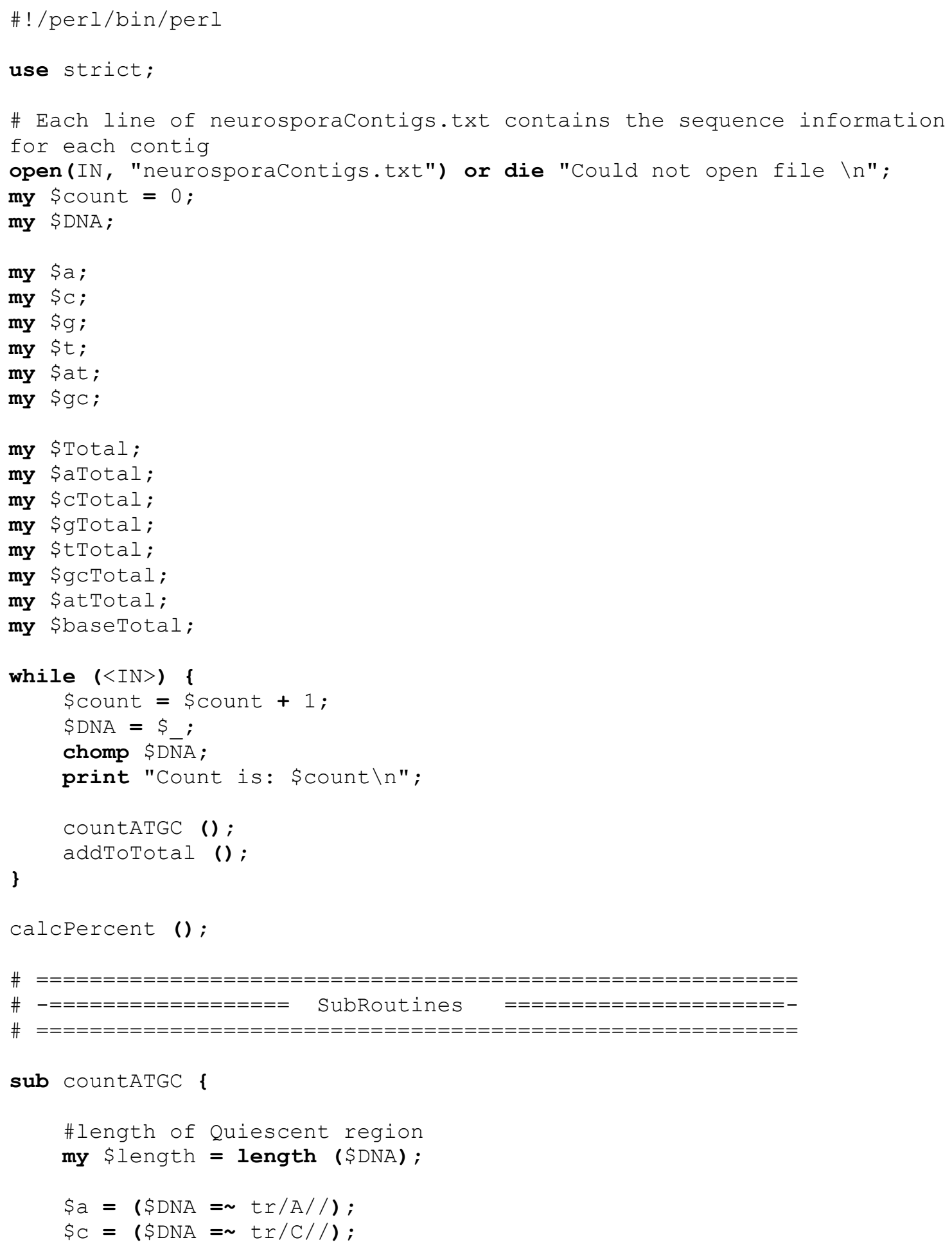




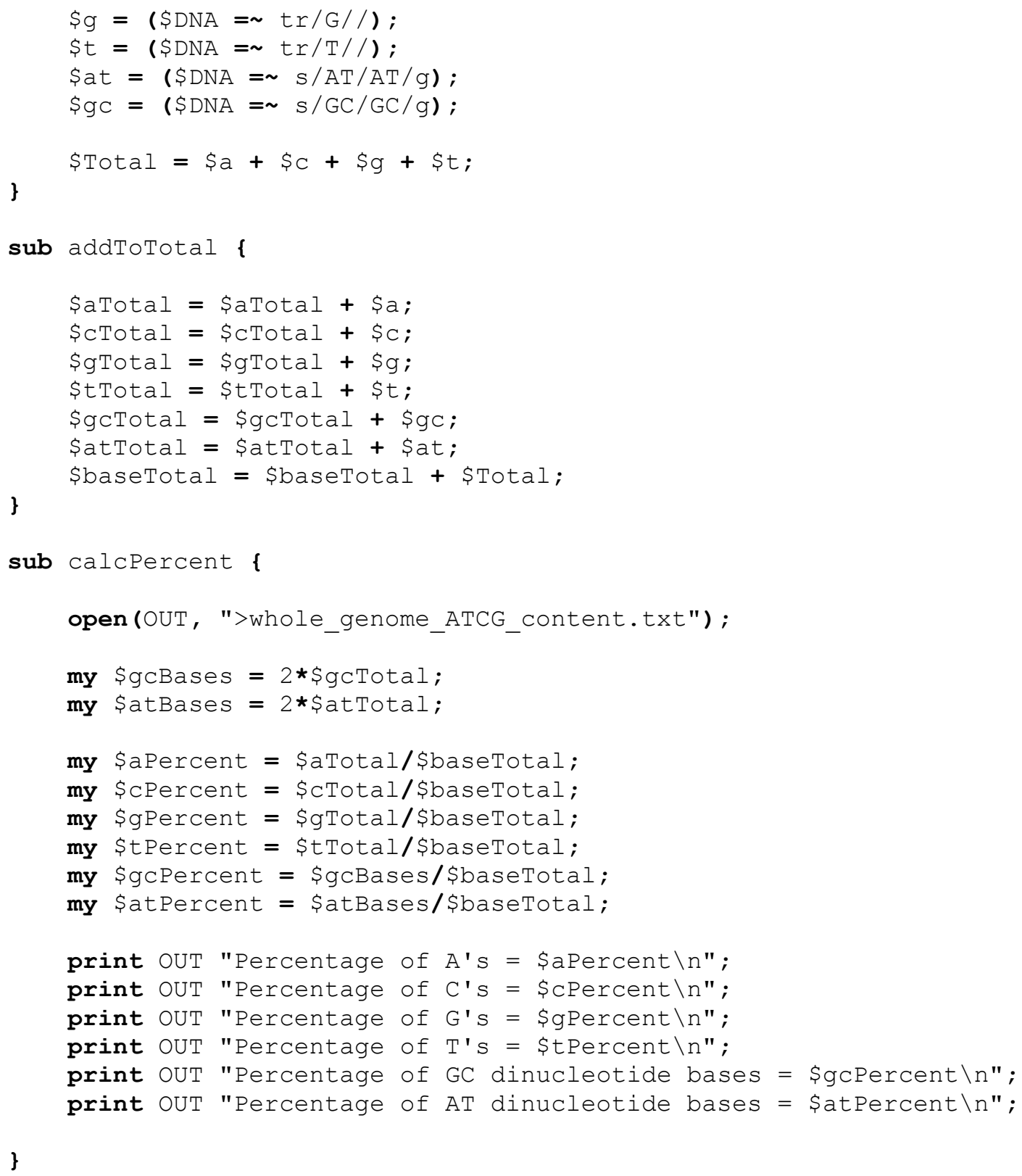

\section{Determine A/T/G/C Content in all Quiescent Regions}

\#! / perl/bin/perl

use strict;

\# Each line of neurosporacontigs.txt contains the sequence information for each contig open(IN1, "neurosporaContigs.txt") or die "Could not open file \n"; my $\$$ count $=0$; my \$DNA; 


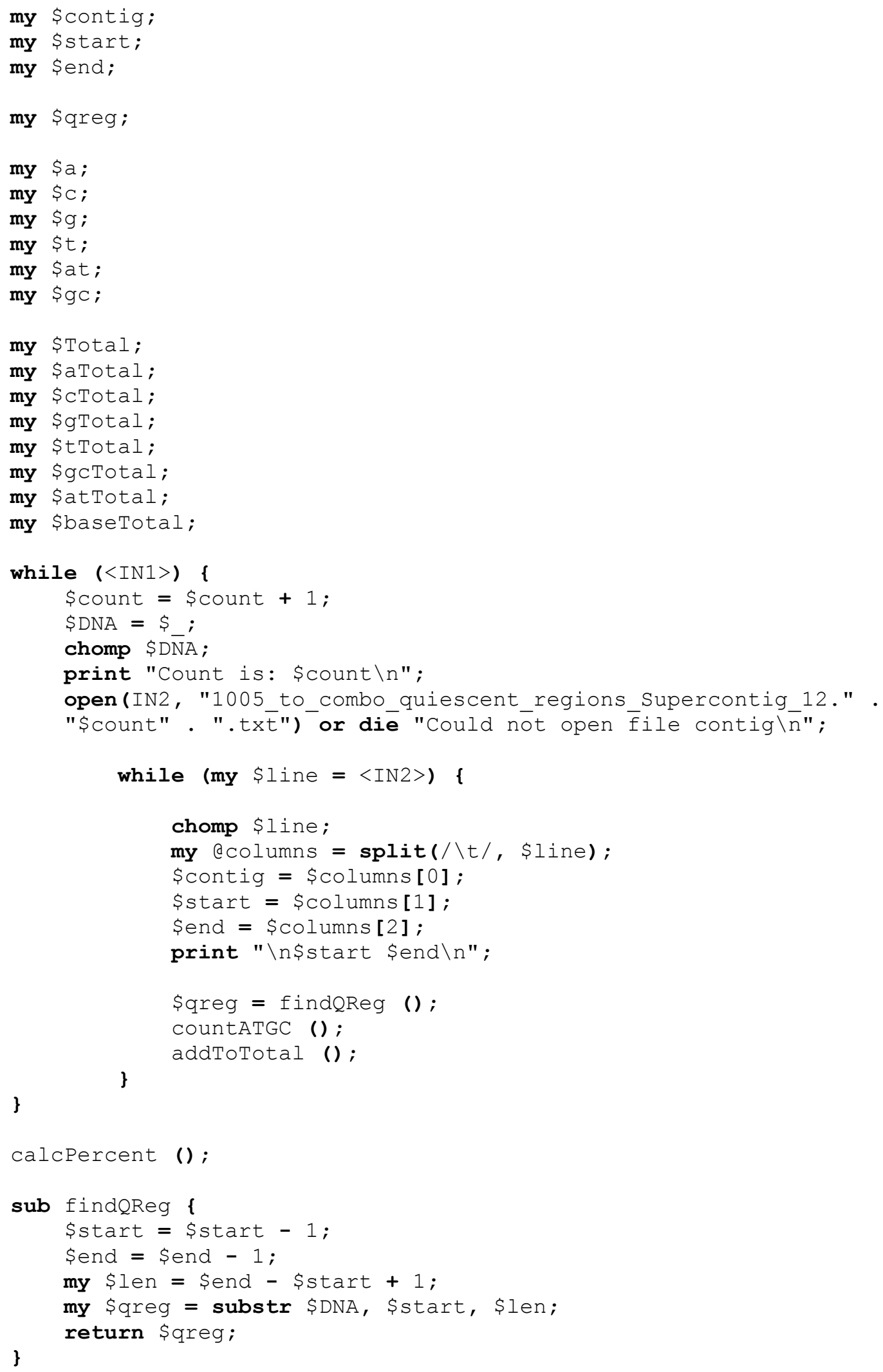




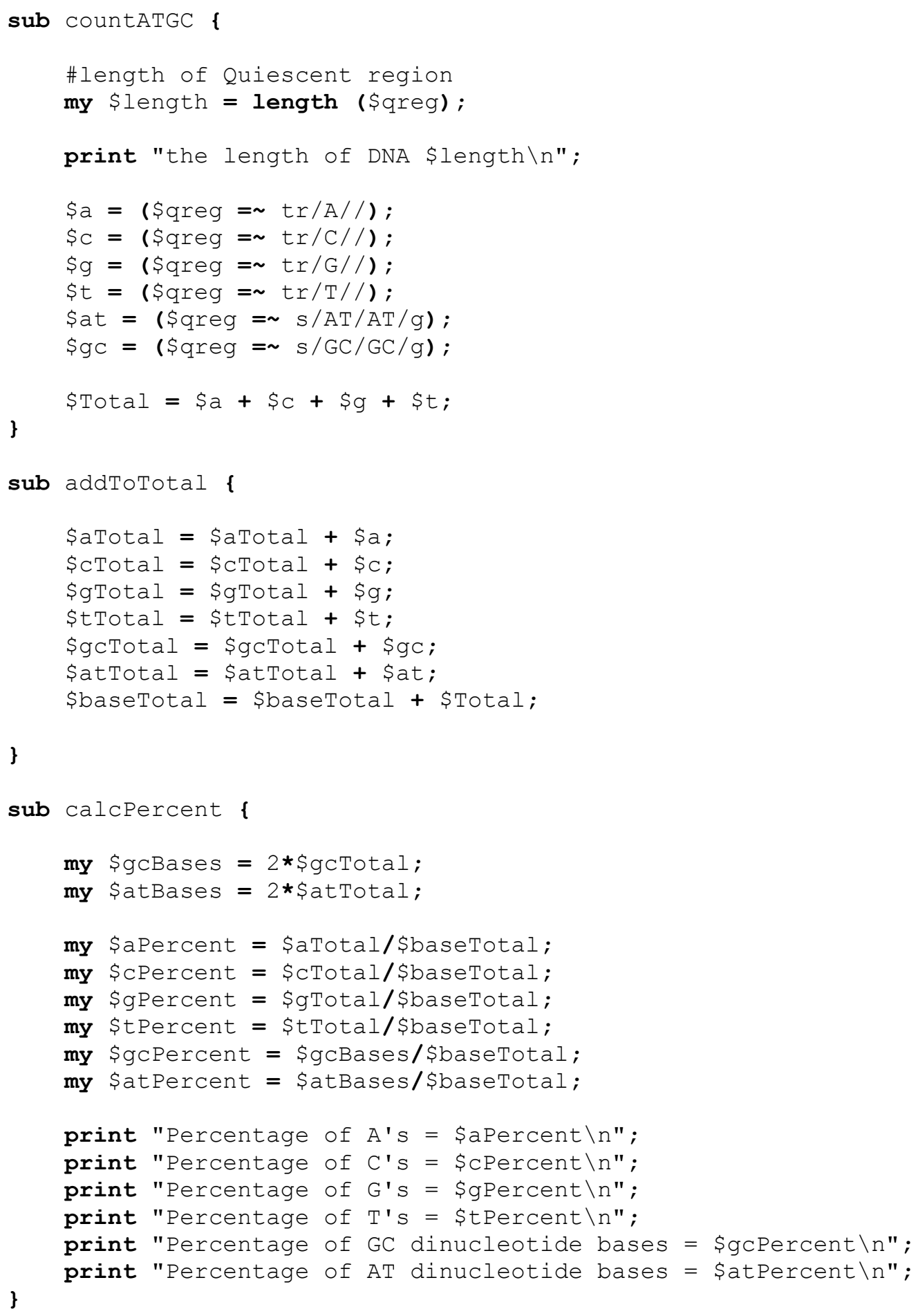

